
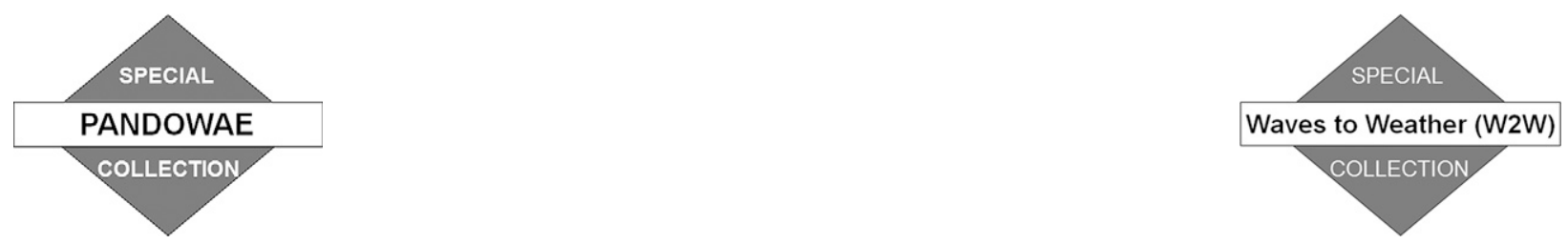

\title{
REVIEW
}

\section{¿The Extratropical Transition of Tropical Cyclones. Part II: Interaction with the Midlatitude Flow, Downstream Impacts, and Implications for Predictability}

\author{
Julia H. Keller, ${ }^{\mathrm{a}, \mathrm{b}}$ Christian M. Grams, ${ }^{\mathrm{c}, \mathrm{d}}$ Michael Riemer, ${ }^{\mathrm{e}}$ HeAther M. ArChambault, ${ }^{\mathrm{f}}$

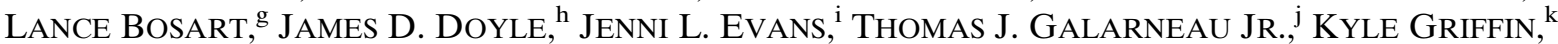 \\ PATRICK A. HARR, ${ }^{1}$ NAOKO KITABATAKE, ${ }^{\mathrm{m}}$ RON MCTAGGART-COWAN, ${ }^{\mathrm{n}}$ FlORIAN PANTILlON,${ }^{\mathrm{d}}$ \\ Julian F. Quinting, ${ }^{\text {o,d }}$ CAROLYn A. REYNOLds, ${ }^{\text {h }}$ ElizABETH A. RitCHIE, ${ }^{\mathrm{p}}$ RYAN D. TORN,${ }^{\mathrm{g}}$ AND \\ FUQING ZHANG ${ }^{\mathrm{i}}$ \\ a Deutscher Wetterdienst, Offenbach, Germany \\ ${ }^{\mathrm{b}}$ World Meteorological Organization, Geneva, Switzerland \\ ${ }^{\mathrm{c}}$ Institute for Atmospheric and Climate Science, ETH Zürich, Zürich, Switzerland \\ ${ }^{\mathrm{d}}$ Institute of Meteorology and Climate Research (IMK-TRO), Karlsruhe Institute of Technology, Karlsruhe, Germany \\ ${ }^{\mathrm{e}}$ Johannes Gutenberg-Universität Mainz, Mainz, Germany \\ ${ }^{\mathrm{f}}$ NOAA/Geophysical Fluid Dynamics Laboratory, Princeton, New Jersey \\ ${ }^{\mathrm{g}}$ Department of Atmospheric and Environmental Sciences, University at Albany, State University of New York, Albany, New York \\ ${ }^{\mathrm{h}}$ Naval Research Laboratory, Monterey, California \\ ${ }^{\mathrm{i}}$ The Pennsylvania State University, University Park, Pennsylvania \\ ${ }^{\mathrm{j}}$ The University of Arizona, Tucson, Arizona \\ ${ }^{\mathrm{k}}$ RiskPulse, Madison, Wisconsin \\ ${ }^{1}$ Naval Postgraduate School, Monterey, California \\ ${ }^{\mathrm{m}}$ Meteorological College, Kashiwa, Chiba, Japan \\ ${ }^{\mathrm{n}}$ Numerical Weather Prediction Research Section, Environment and Climate Change Canada, Dorval, Québec, Canada \\ ${ }^{\circ}$ School of Earth, Atmosphere and Environment, and ARC Centre of Excellence for Climate System Science, \\ Monash University, Clayton, Victoria, Australia \\ ${ }^{\mathrm{p}}$ University of New South Wales, Canberra, Australian Capital Territory, Australia
}

(Manuscript received 9 November 2017, in final form 8 November 2018)

\section{ABSTRACT}

The extratropical transition (ET) of tropical cyclones often has an important impact on the nature and predictability of the midlatitude flow. This review synthesizes the current understanding of the dynamical and physical processes that govern this impact and highlights the relationship of downstream development during ET to highimpact weather, with a focus on downstream regions. It updates a previous review from 2003 and identifies new and emerging challenges and future research needs. First, the mechanisms through which the transitioning cyclone impacts the midlatitude flow in its immediate vicinity are discussed. This "direct impact" manifests in the formation of a jet streak and the amplification of a ridge directly downstream of the cyclone. This initial flow modification triggers or amplifies a midlatitude Rossby wave packet, which disperses the impact of ET into downstream regions (downstream impact) and may contribute to the formation of high-impact weather. Details are provided concerning the impact of ET on forecast uncertainty in downstream regions and on the impact of observations on forecast skill. The sources and characteristics of the following key features and processes that may determine the manifestation of the impact of ET on the midlatitude flow are discussed: the upper-tropospheric divergent outflow, mainly associated with latent heat release in the troposphere below, and the phasing between the transitioning cyclone and the midlatitude wave pattern. Improving the representation of diabatic processes during ET in models and a climatological assessment of the ET's impact on downstream high-impact weather are examples for future research directions.

¿ Denotes content that is immediately available upon publication as open access.

Corresponding author: Julia H. Keller, julia.keller@dwd.de 


\section{Introduction and motivation}

Tropical cyclones (TCs) that move poleward often interact with the midlatitude flow, undergo profound structural changes, and transition into extratropical cyclones. This process is known as extratropical transition (ET; Sekioka 1956; Palmén 1958). In recent years, several ET cases were associated with extreme weather events, thus attracting the attention of the general public. Hurricane Sandy (2012) inflicted widespread damage and severe disruption of public life along the northeast U.S. coast as it underwent ET (Blake et al. 2013; Halverson and Rabenhorst 2013). Hurricane Gonzalo (2014), having undergone ET, tracked across Europe and brought flooding and extreme winds to the Balkans (Brown 2015; Feser et al. 2015). Extreme precipitation associated with Tropical Storm Etau (2015) during and after its ET over Japan flooded areas north and east of Tokyo (AIR Worldwide 2015; Kitabatake et al. 2017). In these examples, the high-impact weather was associated directly with the transitioning cyclone. Such impacts, along with the structural evolution of the cyclone during ET, are discussed in the first part of this review (Evans et al. 2017, hereafter Part I).

Extratropical transition may also lead to high-impact weather far downstream from the actual cyclone. A prominent example for such a "downstream impact" is provided by the ET of Supertyphoon Nuri (2014) in the western North Pacific, displayed in Fig. 1. At the onset of ET, Nuri moves poleward and starts to interact with the midlatitude flow (Fig. 1a). This results in the formation of a jet streak (Fig. 1b) and a poleward deflection of the jet near the transitioning cyclone in conjunction with the development of a ridge-trough couplet (Fig. 1b). At the same time, a region of enhanced moisture flux-a so-called atmospheric river (Zhu and Newell 1998) - forms ahead of the downstream trough. The ridge-trough couplet continues to amplify, a new cyclone develops farther downstream, and the next downstream ridge builds, which signifies the downstream propagation that arises from the initial local changes in the jet near the site of ET (Fig. 1c). Meanwhile, Nuri reintensifies into a strong extratropical cyclone and initiates cyclonic wave breaking over the western North Pacific (Fig. 1c). Subsequently, the upperlevel wave pattern amplifies farther downstream, establishing a high-amplitude ridge-trough couplet over North America. A heat wave develops in the high-pressure conditions along the North American west coast, with highest values occurring along the coast of California and over Alaska. The atmospheric river in the western flank of the second downstream ridge (Fig. 1c) makes landfall in Alaska and British Columbia, resulting in heavy precipitation (Fig. 1d). A cold-air outbreak occurs over continental and eastern North America. Further amplification of this pattern eventually leads to a massive omega block over the west coast of North America and associated cold surges and heavy snowfall in the continental and eastern United States (Bosart et al. 2015). Nuri is just one example of the type of midlatitude flow modification due to ET. The processes acting during such a midlatitude flow modification and the associated implications on downstream extratropical regions are the subjects of this review.

Together with Part I, this review describes developments in our understanding of ET since the first ET review by Jones et al. (2003, hereafter J2003). The review by J2003 was motivated by the challenges that ET typically poses to forecasters in terms of predicting the structural evolution of the transitioning cyclone itself, and the high-impact weather that might be associated with it, mostly in the immediate proximity of the storm. Since the publication of J2003, it has become increasingly apparent that a forecasting challenge is also present for the region downstream of ET because ET often leads to a basin-wide or even hemispheric reduction in the forecast skill of numerical weather prediction (NWP) models. J2003 reviewed the then-current insights into ET and highlighted the need for a better understanding of the physical and dynamic processes involved in ET and their representation in NWP models. Since then, the research community's understanding of the interactions that occur between a transitioning cyclone and the midlatitude flow during ET has progressed considerably. The impact of ET on the midlatitude flow configuration and on predictability both near the transitioning cyclone and in downstream regions has now been quantified. These advancements motivate this second part of the updated review, which synthesizes our current understanding, and highlights open questions and current challenges, thus providing guidance for future research activities.

The structure of the paper largely follows the sequence of processes involved in downstream development during ET and is visualized in Fig. 2. The color of the labels in Fig. 2 indicates the section, whereas the index number refers to the subsection in which these aspects are discussed. Section 2 reviews the impact of ET on the midlatitude flow in the direct vicinity of the transitioning cyclone. The amplification of the downstream ridge, the formation of a jet streak, and the amplification of the downstream trough are discussed in section 2a because this material is key background information for the material that follows. Section $2 \mathrm{~b}$ introduces aspects that arise due to the existence of an upstream trough: the importance of the position of the transitioning cyclone relative to the trough (phasing), the concepts of "phase locking" and associated resonant interaction [section $2 \mathrm{~b}(1)$ ], and the impact of ET on the upstream trough itself [section $2 b(2)]$. Section $2 c$ introduces the idea of "preconditioning": processes that 
(a) TC at transition stage

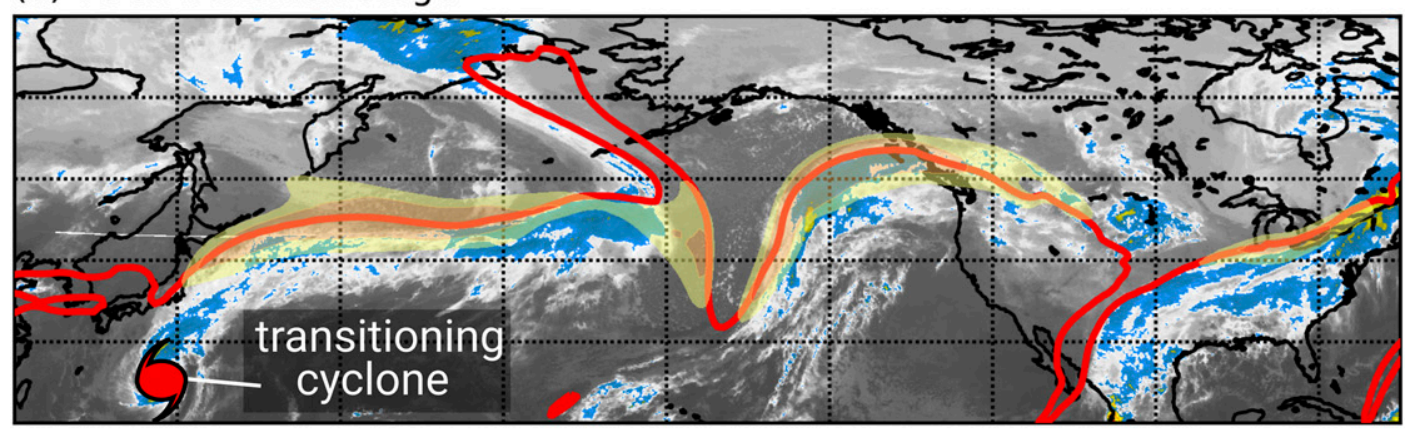

(b) TC-jet interaction

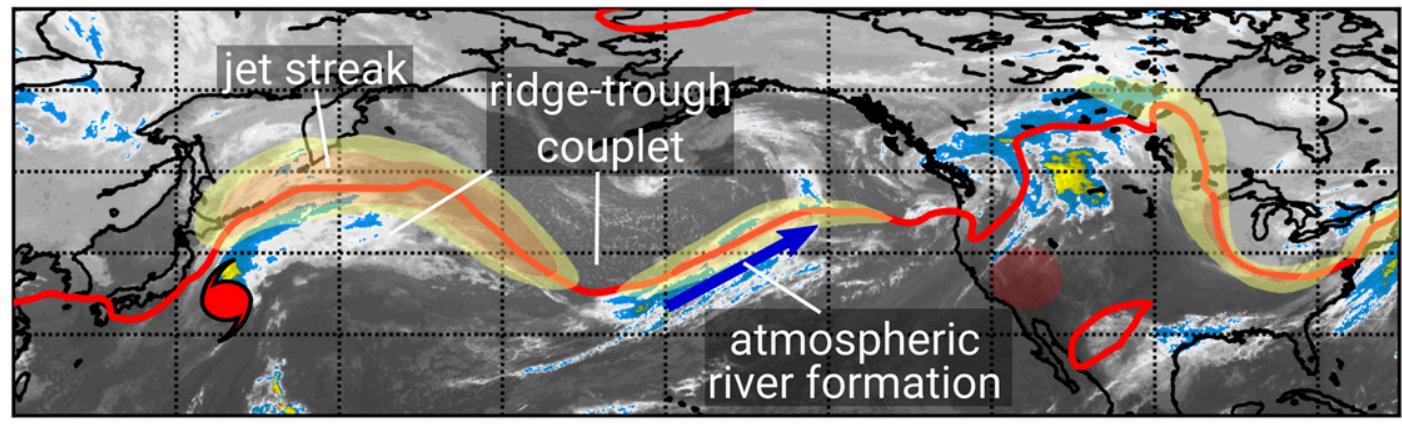

(c) downstream trough/cyclone development

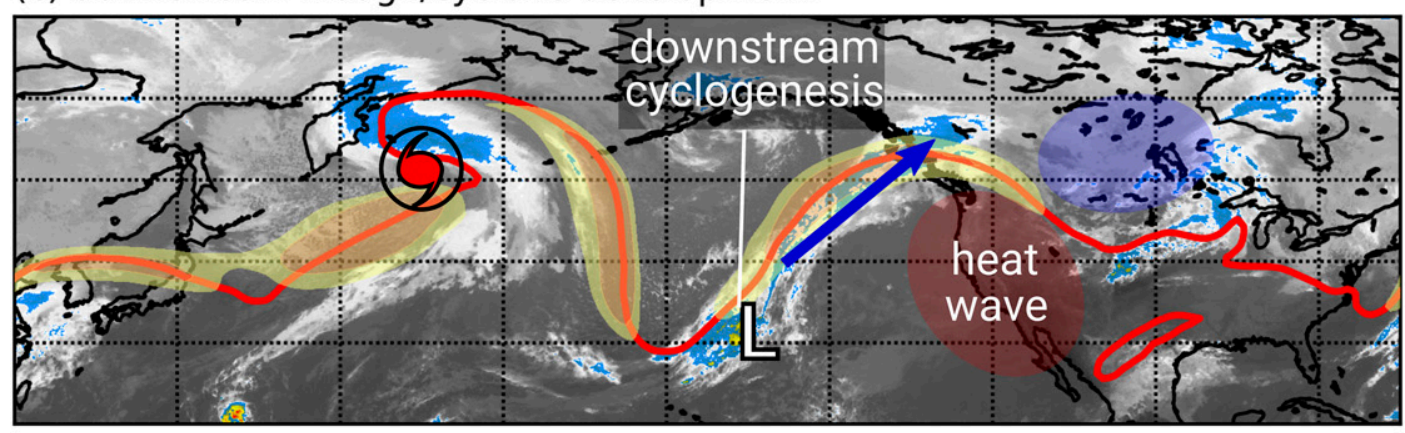

(d) downstream impact (cold air outbreak)

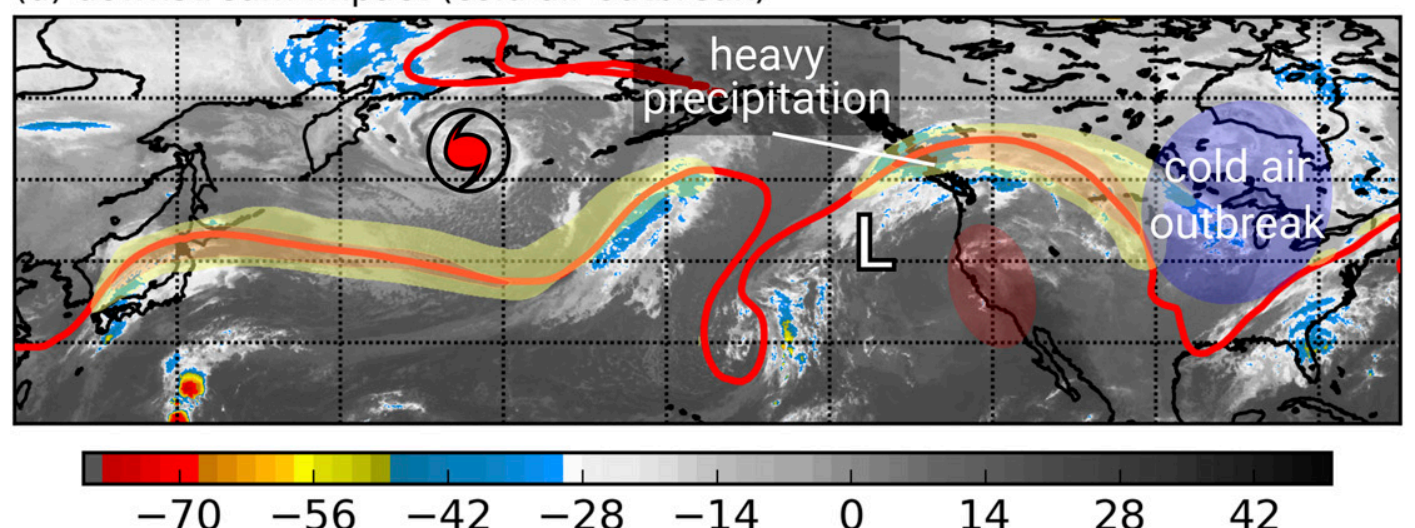

FIG. 1. Downstream development during the ET of Supertyphoon Nuri (2014) at (a) 0600 UTC 5 Nov, (b) 1800 UTC 6 Nov, (c) 1800 UTC 7 Nov, and (d) 0000 UTC 9 Nov 2014. Panels shows IR Gridsat clouds [brightness temperature in ${ }^{\circ} \mathrm{C}$ as in color bar; Knapp et al. (2011)], dynamical tropopause [2 PVU on the 330-K isentropic surface (1 PVU $\left.=10^{6} \mathrm{~K} \mathrm{~kg}^{-1} \mathrm{~m}^{2} \mathrm{~s}^{-1}\right)$; red contour], and wind speed maxima highlighting jet streaks (wind speed on the 330-K isentropic surface as semitransparent shading in yellow for 55 and orange for $65 \mathrm{~m} \mathrm{~s}^{-1}$ ). Dynamical tropopause and wind speed are taken from ERA-Interim. The TC symbol indicates the position of the transitioning cyclone (encircled during extratropical stage) and the " $\mathrm{L}$ " the position of the downstream cyclone. 


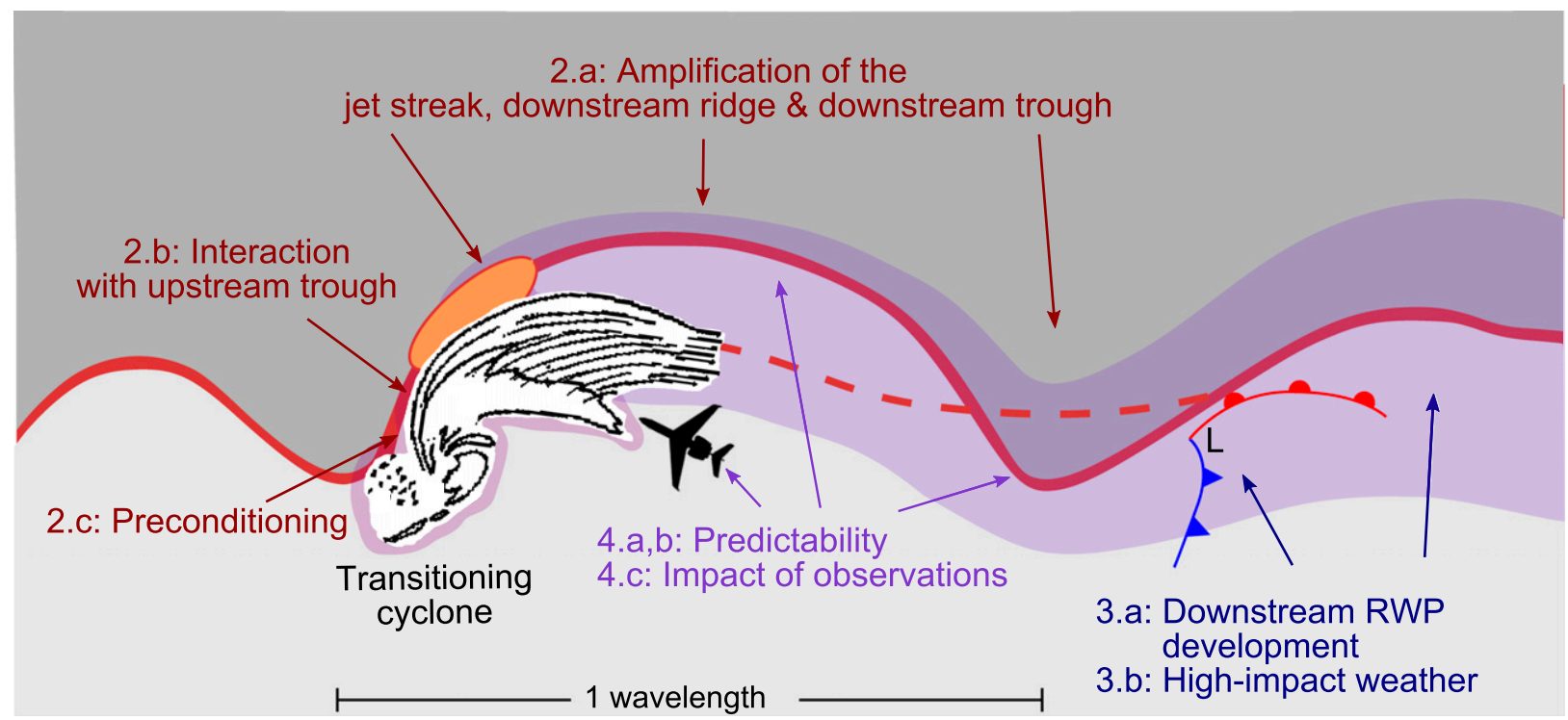

FIG. 2. Overview of synoptic features and processes involved in Northern Hemispheric ET. Labels indicate relevant processes, starting with the section in which they are discussed. Transitioning cyclone presented by the black and white pictogram. The dark red line indicates axis of the undulating midlatitude jet stream separating stratospheric high PV air (dark gray; poleward) and tropospheric low PV air (light gray; equatorward), with the dashed line indicating an alternate configuration. The orange ellipse denotes the jet streak. The purple, semitransparent area signifies the forecast uncertainty for the downstream flow. The downstream cyclone is indicated by the "L" symbol and its associated fronts. The airplane symbol represents observation systems used for ET reconnaissance.

occur before the onset of the actual ET and that promote interaction between the transitioning cyclone and the jet.

The midlatitude flow modifications introduced in section 2 often constitute the amplification or excitation of a Rossby wave packet (RWP; Wirth et al. 2018). Section 3 focuses on the downstream impacts of ET as mediated by RWP amplification or excitation. The modification of midlatitude RWPs by ET is discussed in section 3a. This subsection presents the mechanisms of downstream development during ET [section 3a(1)] before summarizing how RWP amplification during ET manifests in a climatological sense [section 3a(2)]. The contribution of ET to high-impact weather in downstream regions is the subject of section $3 \mathrm{~b}$.

Section 4 reviews predictability aspects (indicated by the semitransparent area enclosing potential alternative flow configurations in Fig. 2). Section 4a presents sources of forecast degradation during ET, whereas section $4 \mathrm{~b}$ describes how forecast uncertainty associated with ET affects prediction downstream of ET. The potential impact of additional and targeted observations on the predictability associated with ET is presented in section $4 \mathrm{c}$.

A summary and a presentation of current challenges and future directions for research are given in section 5 .

\section{Direct impacts on the midlatitude flow}

During ET, the transitioning cyclone typically exerts a direct impact on the midlatitude flow, which manifests in a modification of the jet streak and the ridge-trough couplet immediately downstream of the transitioning cyclone. The processes associated with this impact (red labels in Fig. 2) are the subject of this section. J2003 discussed two mechanisms for this initial modification of the midlatitude flow. First, they hypothesized that the nonlinear-balanced circulation of the transitioning cyclone perturbs the gradient of potential vorticity (PV) associated with the midlatitude jet, thereby exciting RWPs and associated downstream development. The second mechanism occurs through diabatic PV modification and the presence of upper-tropospheric air with anticyclonic PV, ${ }^{1}$ originating from the TC outflow. This second mechanism was rather loosely defined by J2003 but has been described to enhance downstream ridging and jet streak formation and to promote anticyclonic wave breaking. More recent work has confirmed that both mechanisms operate and has clarified their respective roles. Furthermore, a third mechanism has been identified that is arguably the most important individual process: PV advection by the upper-tropospheric divergent outflow.

\footnotetext{
${ }^{1}$ We use the term anticyclonic PV to denote negative PV anomalies in the Northern Hemisphere and positive PV anomalies in the Southern Hemisphere. The term cyclonic PV is used accordingly.
} 
The amplification of the jet streak and of the ridgetrough couplet during ET is reviewed in section $2 \mathrm{a}$. We discuss these processes in the context of wave amplification but stress that ET may also have a detrimental impact on downstream development. Section $2 \mathrm{~b}$ discusses the large sensitivity that the TC-jet interaction exhibits to the relative position of the transitioning cyclone and the upstream trough (referred to as "phasing" hereafter). Section $2 \mathrm{c}$ introduces processes that impact the outcome of ET but occur before the actual ET commences. In this sense, these processes can be conceptually subsumed as preconditioning, a new concept that is not discussed by J2003.

\section{a. Downstream ridge amplification, jet streak formation, and downstream trough amplification}

The amplification (or generation) of a ridge-trough couplet and a jet streak downstream of ET are robust characteristics of the impact of ET on the midlatitude flow. These features have been found in idealized ET scenarios (Riemer et al. 2008; Riemer and Jones 2010), in numerical experiments and process-based analyses of real and composite cases (Agustí-Panareda et al. 2004; Harr and Dea 2009; Grams et al. 2011, 2013a; Griffin and Bosart 2014; Grams and Archambault 2016), in targeted observation studies (Chen and Pan 2010), and from ensemble (Torn 2010; Keller et al. 2014; Keller 2017) and climatological perspectives (Archambault et al. 2013, 2015; Torn and Hakim 2015; Quinting and Jones 2016).

Many of the studies cited above investigated ET from a PV framework, as proposed by J2003. In its most rigorous form, the PV framework considers the full PV budget of a region of interest and yields diabatic and advective PV tendencies [discussion of Eq. (4) by Teubler and Riemer (2016)]. The advective tendencies can be segregated further by carefully partitioning the full flow into distinct anomalies (e.g., Davis and Emanuel 1991). We here briefly introduce the terminology that is used throughout the paper to address the anomalies involved in ET (Figs. 3a,b; based on, e.g., Agustí-Panareda et al. 2004; Riemer et al. 2008). The flow attributed to the transitioning cyclone can be partitioned into three parts:

(i) The balanced (i.e., nondivergent) cyclonic circulation associated with the cyclonic PV tower and with lowlevel cyclonic PV anomalies, diabatically generated at the developing warm front.

(ii) The balanced anticyclonic circulation associated with the anticyclonic PV anomaly of the upper-tropospheric outflow, consisting of air masses that have accumulated in the upper troposphere after having ascended in the presence of latent heat release from the lower troposphere (referred to "outflow anticyclone" in the remainder of the manuscript).

(iii) The upper-tropospheric divergent outflow associated with latent heat release below.

Through "action at a distance," all these features act on the midlatitude PV gradient, as hypothesized by J2003. Spatial integration of the associated PV tendencies over PV anomalies of interest (e.g., those that are associated with the downstream ridge) enables a quantitative assessment of the relative contribution of the advection through these processes to the overall evolution (exemplified in Fig. 3c; further discussed below).

Attributing the cyclonic and anticyclonic balanced circulations to the transitioning cyclone based on PV partition is justified by theory, but the attribution of the upper-tropospheric divergent outflow is not. In the context of ET, the literature agrees on the assumption that PV advection by upper-tropospheric divergent outflow is mostly associated with latent heat release within the transitioning cyclone below. In that sense, this PV advection is considered to be an indirect diabatic process. While the assumption has not yet been tested rigorously, a first test using the framework of the quasigeostrophic omega equation tends to support this assumption (Quinting and Jones 2016).

The formation of a jet streak can be considered from a PV perspective as manifestation of upper-tropospheric frontogenesis (Wandishin et al. 2000). During ET, jet streak formation is enhanced by the upper-tropospheric divergent outflow impinging on the large PV gradient associated with the midlatitude jet (Riemer and Jones 2010; Grams et al. 2013a; Archambault et al. 2013, 2015). Based on a quantitative analysis in an idealized ET scenario, this contribution is arguably as important as that of ongoing upper-tropospheric frontogenesis by the midlatitude dynamics (Riemer and Jones 2010). In addition, the outflow anticyclone constitutes a local elevation of the tropopause on the equatorward side of the jet, with respect to climatology. This elevation may locally increase the slope of the tropopause (i.e., strengthen the PV gradient on an isentrope intersecting the tropopause), thereby accelerating the jet locally and thus contributing to jet streak formation as well (Bosart 2003; Riemer and Jones 2010; Grams et al. 2013a). The latter mechanism has been discussed in a more general context and in a barotropic framework by Cunningham and Keyser (2000).

Complementary to the PV framework, ET can also be considered from a local eddy kinetic energy $\left(K_{e}\right)$ perspective using the downstream baroclinic development paradigm [e.g., Eqs. (2.3) and (2.4) by Orlanski and Sheldon (1995)]. From that viewpoint, the amplification 

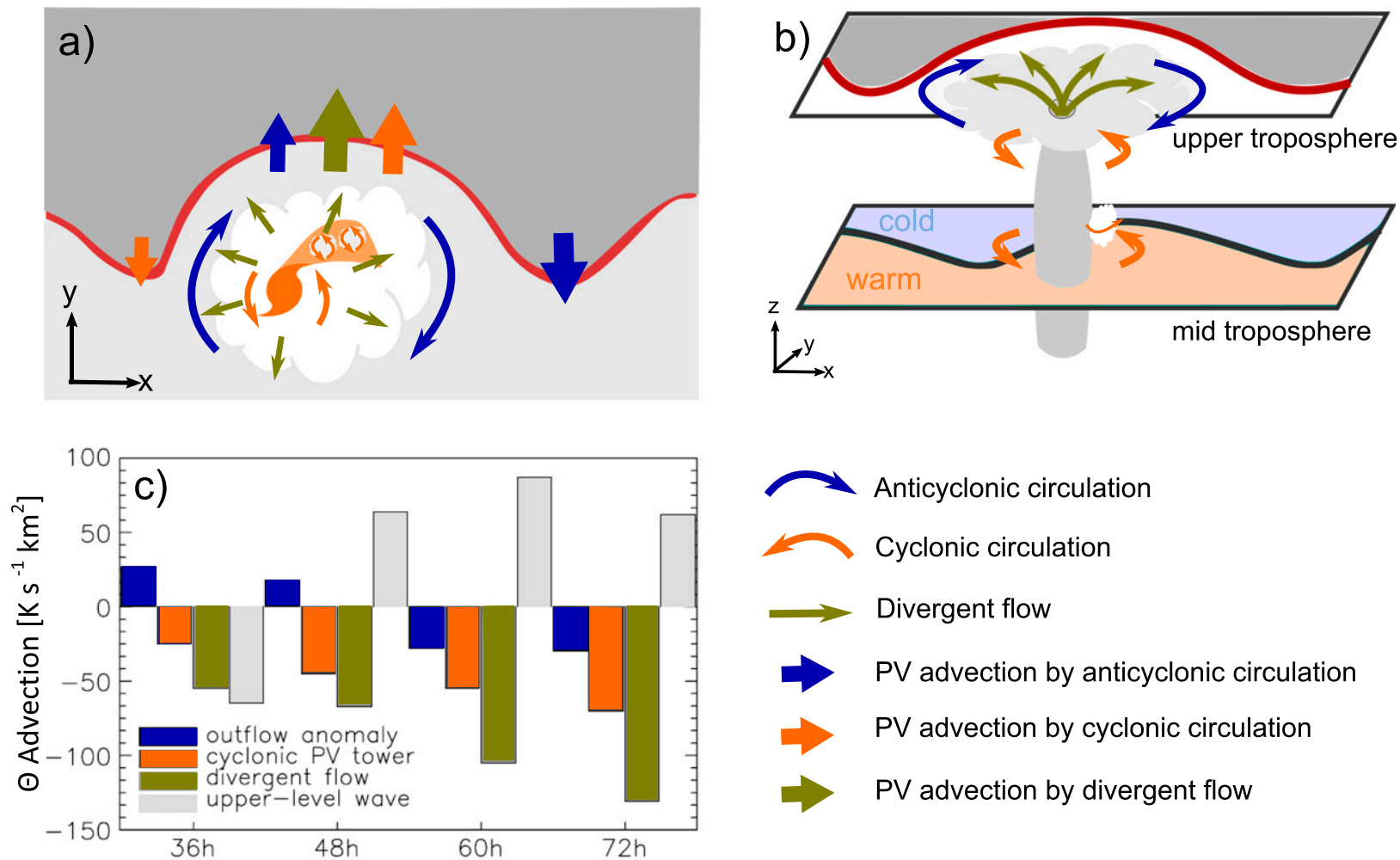

Anticyclonic circulation

Cyclonic circulation

Divergent flow

PV advection by anticyclonic circulation

$\mathrm{PV}$ advection by cyclonic circulation

PV advection by divergent flow

FIG. 3. PV anomalies involved in ET and their respective contribution to RWP modification near ET. The (a) 2D and (b) 3D schematics of the different flow features associated with ET. 1) Cyclonic circulation (thin orange arrows) associated with the cyclonic PV tower [orange TC symbol in (a), gray column in (b)] and with low-level cyclonic PV anomalies (small gray clouds and circulation) at the developing warm front. 2) Anticyclonic circulation associated with the anticyclonic PV anomaly of the upper-tropospheric outflow [white/ gray cloud symbol in (a),(b) and thin blue arrows]. 3) Upper-tropospheric divergent outflow associated with latent heat release below (thin green arrows). The advective contribution of these flow features to the amplification of the downstream ridge and trough are given by the bold arrows in (a). The red contour and shading in (a),(b) are similar to Fig. 2. The lower layer in (b) exemplifies the developing warm front with colder air masses toward the pole. (c) Contributions to ridge amplification from the advection of potential temperature on the dynamic tropopause (a surrogate for upper-level PV advection) by the several flow features, integrated over a ridge for a 72 -h forecast of an idealized scenario [in $\mathrm{K} \mathrm{km}^{2} \mathrm{~s}^{-1}$; colors as in (a),(b)]. [Figure 8 from Riemer and Jones (2010), with modifications.]

of the midlatitude ridge-trough couplet constitutes an increase in midlatitude $K_{e}$, and a jet streak appears as a local maximum in $K_{e}$, with the transitioning cyclone acting as an additional source of $K_{e}$. The notion that ET is a source of midlatitude $K_{e}$ dates back to Palmén (1958). A number of more recent case studies further examined the processes underlying this source (Harr and Dea 2009; Keller et al. 2014; Quinting and Jones 2016; Keller 2017), and a consistent picture has emerged (depicted schematically in Fig. 4a and for a composite of real ET cases in Figs. 4b,c). Rising of warm air, mostly associated with latent heat release in the transitioning cyclone and along the baroclinic zone, releases $K_{e}$ through the baroclinic conversion of eddy available potential energy (Figs. 4a,c). During ET, this $K_{e}$ is redistributed via ageostrophic geopotential fluxes from the transitioning cyclone to the upstream end of the jet streak in the western flank of the ridge, evident by diverging fluxes emerging from the cyclone and converging fluxes in the western flank of the ridge (Figs. 4a,b).
The amplification of the ridge immediately downstream of ET was the focus of many of the studies cited at the beginning of this subsection. This ridge amplification may be vigorous enough to prevail over the ambient midlatitude Rossby wave dynamics. From the PV perspective, advection of anticyclonic PV by the upper-tropospheric divergent outflow makes a major contribution to ridge evolution and tends to dominate ridge amplification during the early phase of ET (Figs. 3a,b; Atallah and Bosart 2003; Riemer et al. 2008; Riemer and Jones 2010, 2014; Torn 2010; Archambault et al. 2013, 2015; Grams et al. 2013a; Lang and Martin 2013; Grams and Archambault 2016; Quinting and Jones 2016). In an idealized ET scenario, this process accounts, on average, for approximately $55 \%$ of the early-phase ridge amplification (from 36 to $72 \mathrm{~h}$ in Fig. 3c; Riemer and Jones 2010).

The source of the latent heat release, with which the upper-tropospheric divergent outflow and thus ridge building is associated, undergoes important changes during ET. 


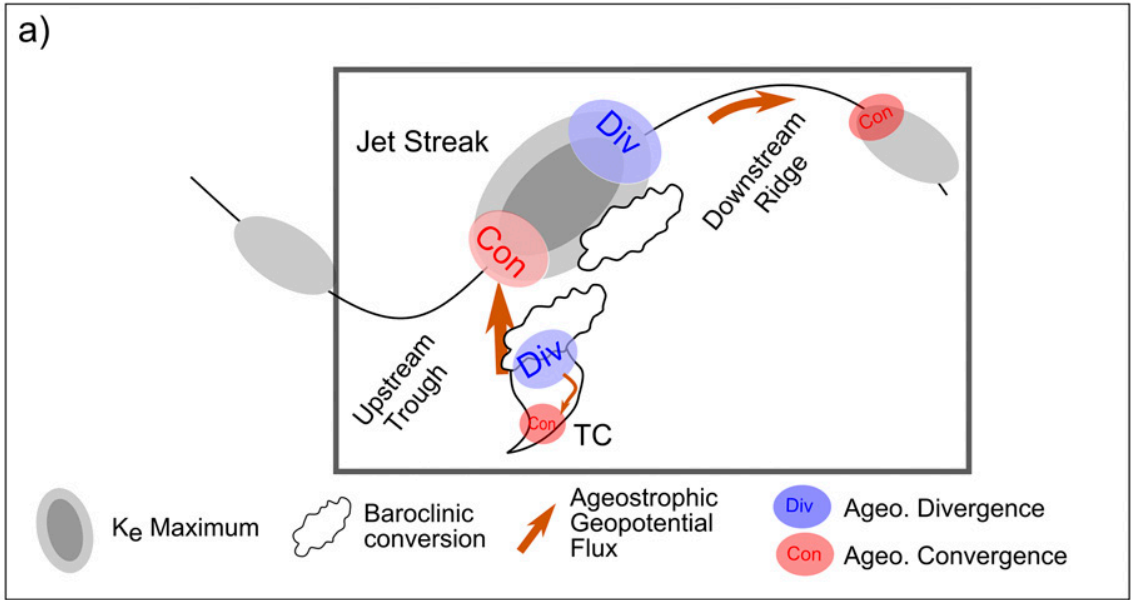

Ageostropic Geopotential Flux

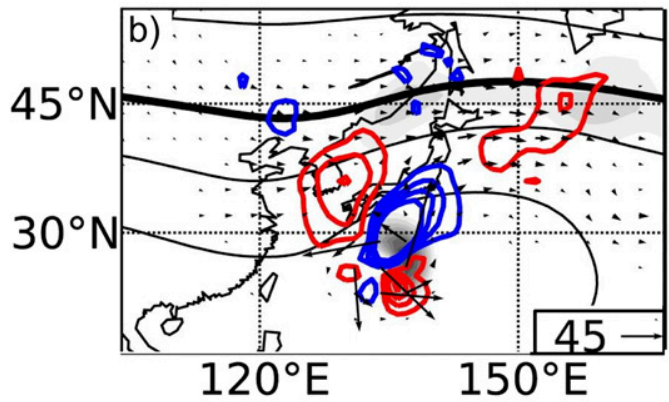

Baroclinic Conversion

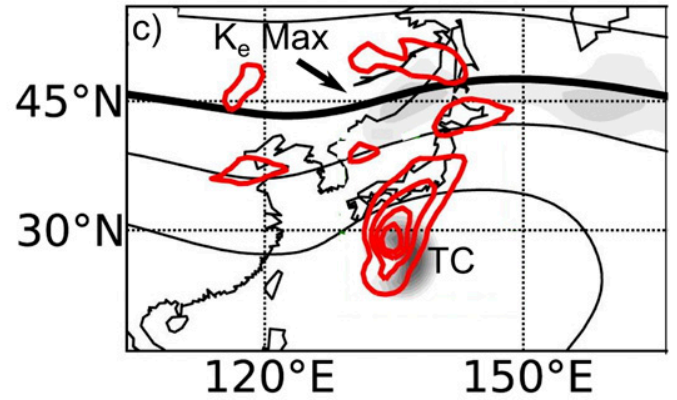

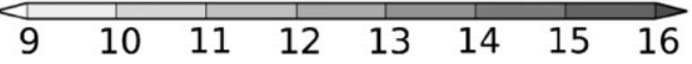

FIG. 4. Jet streak formation during ET from an energetics perspective. (a) Schematic representation, showing midlatitude jet (black line), developing $K_{e}$ maxima (jet streak; gray ellipses), baroclinic conversion of $K_{e}$ (clouds), ageostrophic geopotential flux (orange arrow), and its divergence (blue ellipses) and convergence (red ellipses). (b),(c) TC-relative composite of $K_{e}$ budget for western North Pacific ETs, based on ERA-Interim for 1980-2010 [after Quinting and Jones (2016), their Figs. 12a,b]: vertically integrated $K_{e}$ (shaded in $10^{5} \mathrm{~J} \mathrm{~m}^{-2}$ ), 200-hPa geopotential (contours every $200 \mathrm{~m}^{2} \mathrm{~s}^{-2}$; thick black contour illustrates $11800 \mathrm{~m}^{2} \mathrm{~s}^{-2}$ ), and (b) ageostrophic geopotential flux (vectors, reference vector in $10^{6} \mathrm{~W} \mathrm{~m}^{-1}$; divergence as colored contours every $8 \mathrm{~W} \mathrm{~m}^{-2}$, divergence in blue, $0 \mathrm{~W} \mathrm{~m}^{-2}$ omitted) and (c) vertically integrated baroclinic conversion of $K_{e}$ (red contours every $8 \mathrm{~W} \mathrm{~m}^{-2}$ ). The black box approximates the area that is captured by (b),(c). Composites are shown relative to the mean TC position.

Early during ET, ascent and associated latent heat release occurs mainly in the convection near the cyclone center (exemplified by trajectories depicted in Fig. 5a). At the same time, the cyclonic circulation of the transitioning cyclone advects warm and moist air masses out of the tropics toward the midlatitudes. When impinging on the baroclinic zone (Figs. 5a,b), these air masses begin to ascend slantwise along the sloping moist isentropes and convective bursts with associated latent heat release develop, usually poleward and east of the transitioning cyclone (Torn 2010; Grams et al. 2013a). During ET, these air masses become more stable, and saturated ascent becomes predominantly slantwise along the front (Fig. 5b), signifying the gradual evolution of a warm conveyor belt in the developing warm sector of the transitioning cyclone at later stages of ET
(Agustí-Panareda et al. 2004; Evans and Hart 2008; Torn 2010; Grams et al. 2011, 2013a). The slantwise frontal ascent might still contain embedded convective cells. It thus seems plausible that the "elevator-escalator" perspective of Neiman et al. (1993), which describes ascent in the warm sector of extratropical cyclones as a combination of slantwise frontal upglide (escalator) and mesoconvective updrafts (elevator), also holds true for warm-frontal ascent during ET.

Advection of anticyclonic PV into the ridge by the cyclonic circulation associated with the transitioning cyclone, as hypothesized by $\mathrm{J} 2003$, is another contributor to ridge amplification (Fig. 3a; Riemer et al. 2008; Riemer and Jones 2010, 2014; Quinting and Jones 2016). This contribution to ridge amplification increases during ET as the cyclone moves closer to the midlatitude PV 
Lagrangian trajectories showing ascent during different stages of Typhoon Jangmi's ET
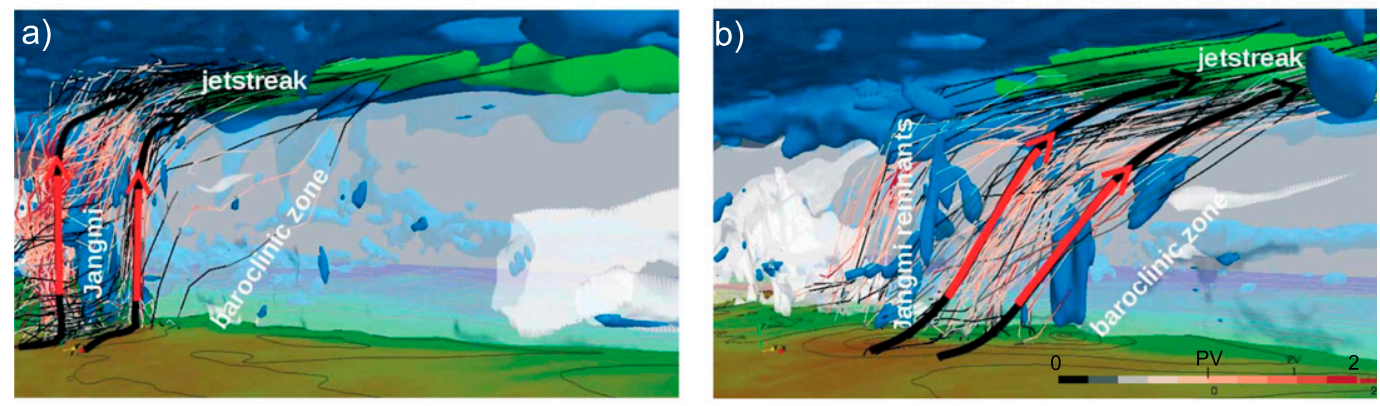

FIG. 5. Lagrangian trajectories for the ET of Typhoon Jangmi showing ridge building and jet streak formation at (a) 0000 UTC 30 Sep and (b) 1200 UTC 1 Oct 2008. Shown are the 1.5-PVU surface (blue shading), 320-K surface of equivalent potential temperature (transparent gray shading), representing 3D baroclinic zone; $|\mathbf{V}|=60 \mathrm{~m} \mathrm{~s}^{-1}$ (green shading), highlighting upper-level midlatitude jet; potential temperature at $990 \mathrm{hPa}$ (shading at bottom; brown colors $>300 \mathrm{~K}$, green $\approx 290 \mathrm{~K}$ ) and geopotential height at $990 \mathrm{hPa}$ (black contours; every $25 \mathrm{dam}$ ). Paths of representative trajectories [(a) 1200 UTC 28 Sep-1200 UTC 30 Sep 2008 and (b) 1200 UTC 30 Sep-1200 UTC 2 Oct 2008] colored by PV of air parcel moving along trajectory. Anticyclonic PV air (PV $<0.6 \mathrm{PVU})$ in gray shades and cyclonic PV values (PV > 0.6 PVU) in red shades (see legend in bottom right). [Figure 5 from Grams et al. (2013a).]

gradient, and it may become the dominant process for ridge building during the late stage of ET (Riemer et al. 2008; Riemer and Jones 2014).

In addition to the amplification of the downstream ridge, a transitioning cyclone directly amplifies the downstream trough through equatorward advection of cyclonic PV by the outflow anticyclone (Fig. 3a). This process has been observed in real cases and in idealized scenarios (Lazear and Morgan 2006; McTaggart-Cowan et al. 2006b; Riemer et al. 2008; Riemer and Jones 2010, 2014; Grams et al. 2013a,b; Grams and Blumer 2015; Grams and Archambault 2016). Furthermore, the presence of the outflow anticyclone implies an enhanced anticyclonic flow component in the region of the downstream trough and thereby indeed favors anticyclonic breaking of this trough (Riemer et al. 2008; Riemer and Jones 2010, 2014), as originally hypothesized by J2003. The advection of anticyclonic and cyclonic PV contribute equal to the direct amplification of the downstream ridge and trough, respectively, in the idealized scenario of Riemer and Jones (2014). Future studies, however, are needed to clarify the relative importance of both processes in the real atmosphere.

The PV and $K_{e}$ frameworks provide complementary and broadly consistent views on the modification of the midlatitude flow by ET. Arguably, the $K_{e}$ perspective provides a simpler general picture, whereas the strength of the PV perspective is apparent in the more detailed examination of individual processes. Note that individual terms in the respective budget equations of $K_{e}$ and PV cannot be compared one to one. The two frameworks differ in particular in their interpretation of the secondary circulation associated with latent heat release. In the $K_{e}$ perspective, the ascent associated with latent heat release is diagnosed as contributing to baroclinic conversion. The upper-tropospheric divergent outflow contributes to the ageostrophic geopotential flux. In an isentropic PV framework, (generalized) vertical motion is represented by diabatic heating, and hence diabatic PV modification is directly diagnosed. The upper-tropospheric divergent outflow is diagnosed as a separate process. More details on the differences between the two frameworks are provided by Teubler and Riemer (2016) and Wirth et al. (2018). Interpreting PV advection by the divergent flow as an indirect diabatic impact relies on the assumption that secondary circulations associated with dry, balanced dynamics are considerably smaller than those associated with latent heat release, at least near the transitioning cyclone. A rigorous test of this assumption is still missing. Arguably, connecting the PV framework with Lagrangian trajectory diagnostics yields the most comprehensive view on diabatic PV modification and cross-isentropic flow. The different manifestations of diabatic processes in the $K_{e}$ and in the PV framework need to be kept in mind when interpreting the results.

In conclusion, the hypothesis of J2003 that the balanced circulation of the transitioning cyclone perturbs the midlatitude PV gradient has been largely confirmed: the cyclonic circulation contributes to ridge building and the anticyclonic circulation of the outflow anomaly to trough amplification downstream. Arguably the largest individual contributor to ridge building, as well as jet streak formation, however, is the upper-tropospheric divergent outflow, which undergoes important changes during ET. While J2003 hypothesized on the role of upper-tropospheric air 
with anticyclonic $\mathrm{PV},{ }^{2}$ which is usually found within the divergent outflow, this important contribution of the divergent flow in modifying the midlatitude flow was not considered explicitly.

\section{b. Interaction and phasing of transitioning cyclone with upstream trough}

The interaction between the transitioning cyclone and the midlatitude flow, and thus the amplification of the downstream ridge and the formation of the jet streak, strongly depends on the relative spatial position of the transitioning cyclone and the upstream trough. The importance of this "phasing" as a major source of forecast uncertainty was identified by J2003. Through idealized (Ritchie and Elsberry 2003, 2007; Riemer et al. 2008; Riemer and Jones 2010; Scheck et al. 2011a,b) and real case studies (Grams et al. 2013b) and a climatological assessment (Archambault et al. 2013, 2015; Quinting and Jones 2016; Riboldi et al. 2019), it is now clear that phasing and the interaction of the transitioning cyclone with the upstream trough determines the downstream development during ET.

\section{1) Phasing, PHASe LOCKing, AND Resonant INTERACTION}

Phasing determines whether a transitioning cyclone moves into an area that is favorable to midlatitude cyclone development or not. Typically, the region ahead of an upper-tropospheric trough is considered favorable, as can be quantified by evaluating Petterssen development parameters $^{3}$ (Petterssen and Smebye 1971). As described in Part I, TCs that track into such a region ahead of the trough reintensify as extratropical cyclones, which means that their phasing with the midlatitude flow is favorable. In contrast, TCs that miss this region of favorable conditions tend to decay after ET (Klein et al. 2002; Ritchie and Elsberry 2003, 2007; Grams et al. 2013b). Transitioning TCs that undergo reintensification as extratropical cyclones support stronger amplification of the downstream ridge through the processes explained in section 2a and may lead to strong downstream impacts (section 3; Archambault et al. 2013; Grams et al. 2013b). In contrast to phasing, the initial size and strength of the TC, or the initial amplitude of the upstream trough, are secondary to the intensity evolution

\footnotetext{
${ }^{2}$ Direct diabatic PV modification, as diagnosed by the diabatic term in the PV equation, has been of secondary importance in all studies that have performed PV budget analysis and hence is not discussed in this review.

${ }^{3}$ These are, for example, upper-tropospheric divergence, lowertropospheric warm-air advection, and midtropospheric cyclonic vorticity advection.
}

in the extratropical phase of ET (Ritchie and Elsberry 2003) or the magnitude of the downstream impact (Quinting and Jones 2016; Riboldi et al. 2018, 2019).

This high sensitivity to phasing can be traced back to the existence of a bifurcation point in the steering flow near the tip of the upstream trough in a trough-relative frame of reference; that is, the full flow minus the phase speed of the trough (arrows in Fig. 6; Scheck et al. 2011b; Grams et al. 2013b; Riemer and Jones 2014). Near such a bifurcation point (dot in Fig. 6), small differences in the position of the transitioning cyclone lead to large differences in the subsequent cyclone track (black lines in Fig. 6). The cyclones either track northeastward and undergo ET or continue their westward movement without undergoing ET, which means that the highly sensitive behavior around the bifurcation point translates into a high sensitivity of whether or not the transitioning cyclone recurves (changes its motion component from westward to eastward relative to the trough), reintensifies, and potentially exerts a pronounced downstream impact (Grams et al. 2013b). A second bifurcation point near the tip of the downstream ridge (cross in Fig. 6) apparently distinguishes between transitions into either the northwest or the northeast circulation pattern introduced by Harr et al. (2000; see also Riemer and Jones 2014). Bifurcation points also exist for the potential interaction of the cyclone with uppertropospheric cutoff lows. In this case, the interaction can be interpreted as vortex-vortex interaction, leading to the eventual merger or escape of the vortices [e.g., in the case of Hurricane Nadine (2012); Pantillon et al. 2016; Munsell et al. 2015].

In general, phasing evolves with time. There are processes, however, that promote a near-constant phasing over an extended period of time, referred to as phase locking. One such process is advection of midlatitude PV by the circulation associated with the outflow anticyclone (Fig. 3), which reduces the phase speed of the midlatitude Rossby wave and brings it closer to the translation speed of the transitioning cyclone (Riemer et al. 2008). In case of phase locking, the transitioning cyclone persistently amplifies the downstream ridge-trough couplet. In this sense, ET can be considered as a resonant interaction (Hodyss and Hendricks 2010; Scheck et al. 2011a,b), with the transitioning cyclone acting as a long-lived, local wave maker (Riemer et al. 2008) that moves in phase with the wave. Therefore, phase-locked configurations promote pronounced downstream impacts (Grams et al. 2013b; Riboldi et al. 2019) and favor strong reintensification of the transitioning cyclone after ET (Ritchie and Elsberry 2007). The local wave initiation and resonant interaction ideas imply that the transitioning cyclone constitutes an 


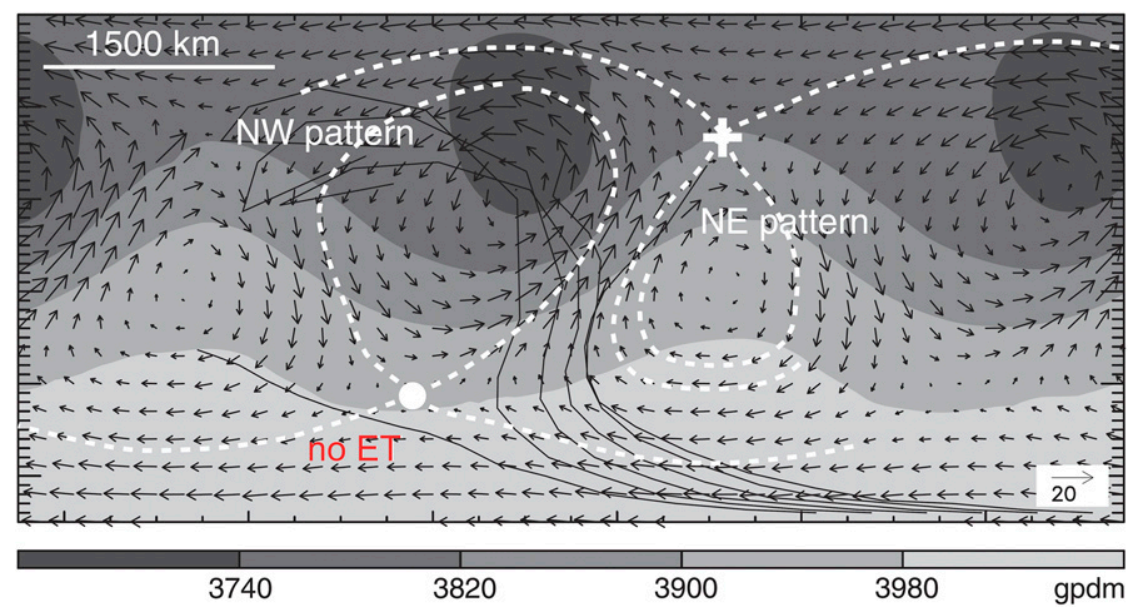

FIG. 6. Idealized scenario for steering flow topology during ET. Midtropospheric geopotential to illustrate the midlatitude wave pattern and winds in the frame of reference moving with this pattern (at $620 \mathrm{hPa}$; shaded and arrows, respectively) and different tracks of transitioning cyclones from sensitivity experiments (thin black lines). The bifurcation points associated with the upstream trough and the developing downstream ridge, deciding upon the development of a "no ET," an "NW pattern," or an "NE pattern" scenario, are marked by the dot and the cross, respectively. Dashed contours depict the streamlines that emanate from the bifurcation points. [Figure 11 from Riemer and Jones (2014).]

external forcing with persistent structure to the midlatitude wave. This idea is in marked contrast to traditional initial-value studies of baroclinic development, in which the initial perturbations are embedded in the midlatitude flow and are thus not an external forcing (e.g., Simmons and Hoskins 1979; Hakim 2000).

\section{2) EVOlution OF THE UPSTREAM TROUGH}

ET may also influence the upstream trough, which may experience modifications of its shape, meridional extension, and eventually break. These modifications influence phasing and thereby the overall flow evolution during ET.

The cyclonic circulation of the transitioning cyclone (Fig. 3a) impinging on the upstream trough may lead to trough amplification and/or thinning, as well as to a subsequent cyclonic wrap-up (McTaggart-Cowan et al. 2001; Agustí-Panareda et al. 2005; Riemer et al. 2008; Grams et al. 2011; Griffin and Bosart 2014; Riemer and Jones 2014; Quinting and Jones 2016). The upstream trough may further be modified by the uppertropospheric divergent outflow, which might hinder the downstream propagation and cyclonic breaking of the trough. This hindering of downstream propagation may lead to trough thinning and the formation of a PV streamer (Agustí-Panareda et al. 2004; Grams et al. 2011; Pantillon et al. 2013a; Riemer and Jones 2014).

Interestingly, the observed impacts on the upstream trough during ET differ for different ocean basins and are sensitive to the large-scale midlatitude circulation pattern (J2003; Agustí-Panareda et al. 2005). Western North
Pacific ETs tend to be associated with anticyclonic wave breaking and the formation of cutoff lows (i.e., the evolution follows the anticyclonic baroclinic life cycle paradigm; Davies et al. 1991; Thorncroft et al. 1993). Atlantic ETs tend to follow the cyclonic baroclinic life cycle with a cyclonic wrap-up of the trough and the formation of a broad and deep surface low (J2003 and references therein; Röbcke et al. 2004; Agustí-Panareda et al. 2004, 2005; Grams et al. 2011). The reasons for these differences in wave breaking and whether such large-scale circulation patterns associated with ET also exist in other ocean basins have not been investigated yet.

In conclusion, the relative position between the transitioning cyclone and the upstream trough (i.e., phasing) is crucial in determining the reintensification of the transitioning cyclone as an extratropical cyclone, the amplification of the downstream ridge-trough couplet, as well as the downstream impact of ET (in terms of RWP amplification). A reduction in the eastward propagation of the upstream trough by the divergent outflow and the cyclonic circulation of the TC, and a reduction of the phase speed of the RWP by the outflow anticyclone, may result in a phase-locked configuration. In this case, the transitioning cyclone and the upstream trough move in phase, and quasi-resonant interaction maximizes the amplification of the downstream ridge.

\section{c. Preconditioning stage and predecessor rain events}

The direct interaction between the transitioning cyclone and the midlatitude flow, as described above, might be 


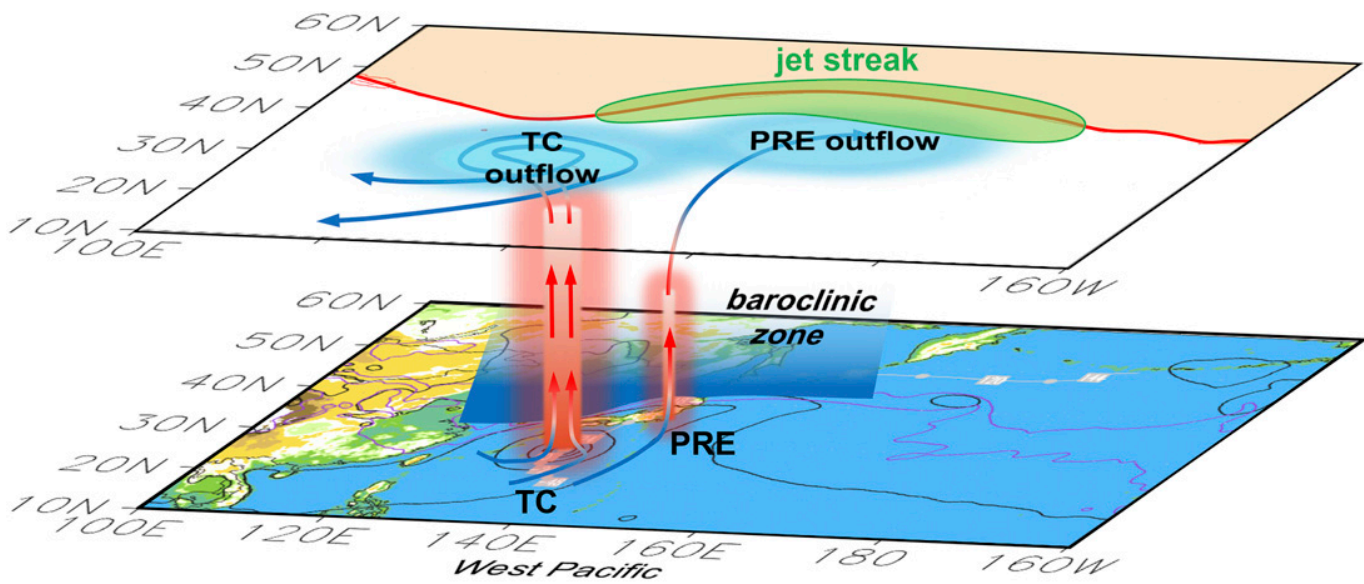

FIG. 7. Three-dimensional schematic depiction of the preconditioning stage with a PRE during western North Pacific ET anticyclonic PV air in the upper-level outflow of a TC and associated PRE as blue shading in the upper panel, and jet streak as green shading and 200-hPa waveguide as red contour separating high PV air ( $>3$ PVU; orange shading) from lower PV air ( $<3$ PVU; unshaded). Midlevel baroclinic zone as blue tilted surface. Trajectories of rapidly ascending air parcels as blue-red-blue lines, reflecting the diabatic PV modification of the parcels from low to high to low PVU, respectively. Mean sea level pressure (gray contours; every $8 \mathrm{hPa}$ ) and equivalent potential temperature (violet contours; 320 and $330 \mathrm{~K}$ ) are indicated in the lower panel. [Figure 11a from Grams and Archambault (2016).]

preceded by processes that establish an extratropical environment that supports baroclinic development (preconditioning stage; Grams and Archambault 2016). J2003 mentioned the occasional occurrence of heavy precipitation events well poleward of the transitioning cyclone, which now have been established as so-called "predecessor rain events" (PRE; Cote 2007). Here, we consider the occurrence of PREs in the broader context of preconditioning.

Common to all processes involved in preconditioning is the poleward transport of warm and moist air of tropical origin (see Fig. 7 for the example of a PRE event). This transport can be facilitated if the transitioning cyclone recurves into a highly amplified wave pattern that yields a strong poleward steering flow (McTaggart-Cowan et al. 2006a,b). Alternatively, the poleward advection of tropical air masses may occur along the eastern side of a recurving TC and along the western flank of the subtropical high, showing the characteristics of a baroclinic moisture flux (McTaggartCowan et al. 2017).

During the preconditioning stage, exemplified for a PRE in Fig. 7, this tropical air impinges on the midlatitude baroclinic zone or experiences upper-tropospheric forcing for ascent ahead of the upstream trough (Fig. 7). The resulting ascent of the warm and moist tropical air mass may support extratropical cyclogenesis, the formation of a diabatic Rossby wave (Grams 2011, 2013; Riemer et al. 2014), or result in stationary heavy precipitation due to PREs well poleward of the transitioning cyclone.
The upper-tropospheric divergent outflow associated with latent heat release in such a precursor weather system may initiate ridge building and jet acceleration (Fig. 7), similar to the transitioning cyclone itself (section 2a; Grams and Archambault 2016). Thus, prior to the onset of ET, these weather systems establish an extratropical environment that is characterized by an upstream trough and a downstream ridge, a flow configuration that may support the extratropical reintensification of the transitioning cyclone later (Fig. 7; Grams and Archambault 2016), and thus impacts the outcome of ET.

PREs are a particular type of preconditioning and have been studied extensively (e.g., Bosart and Carr 1978; Cote 2007; Stohl et al. 2008; Wang et al. 2009; Galarneau et al. 2010; Schumacher et al. 2011; Bosart et al. 2012; Byun and Lee 2012; Schumacher and Galarneau 2012; Cordeira et al. 2013; Baek et al. 2013; Moore et al. 2013; Parker et al. 2014; Bao et al. 2015; Galarneau 2015). PREs are regions of quasi-stationary convection and heavy precipitation that occur about $500-2000 \mathrm{~km}$ poleward of a recurving TC (Fig. 13 in Bosart and Carr 1978) and may develop in different synoptic-scale flow patterns (Moore et al. 2013). In general, PREs develop along a baroclinic zone when tropical air associated with the TC is ascending ahead of a trough and in the vicinity of a jet streak (Fig. 8). This results in heavy precipitation (Fig. 8; yellow-green ellipse) and associated diabatically enhanced upper-level outflow. Because of their preconditioning effect on the midlatitude flow, PREs may also influence the track of the transitioning cyclone (Galarneau 2015). About one-third of the 


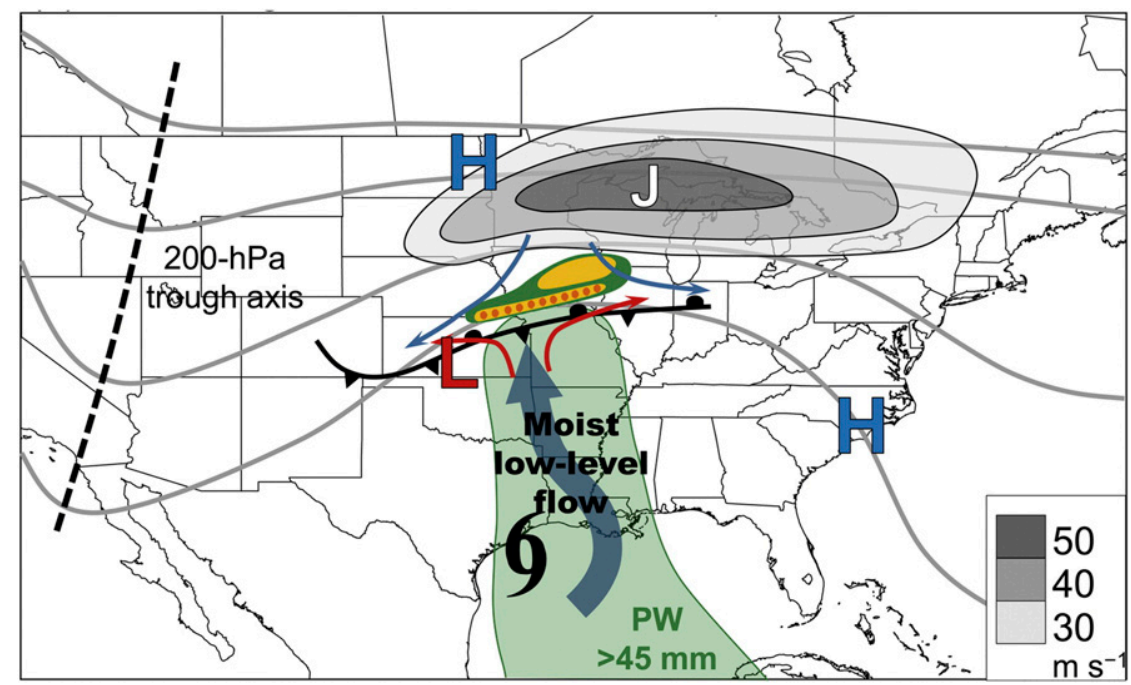

FIG. 8. Conceptual model of the key synoptic-scale features during the occurrence of a PRE. Shown is the 200-hPa geopotential height (contours), the upper-tropospheric jet streak (gray shading), the midlatitude baroclinic zone [surface frontal structure with $925-\mathrm{hPa}$ streamlines associated with warm (red) and cold (blue) air advection], and lower-tropospheric moisture flux along the eastern side of the recurving TC and the western flank of a subtropical high. The formation of the PRE is indicated by the yellow-green ellipse. [Fig. 20a of Moore et al. (2013).]

North Atlantic TCs that made landfall in the United States between 1998 and 2006 produced at least one PRE (Cote 2007). Several PREs were associated with record-breaking amounts of precipitation (e.g., $500 \mathrm{~mm}$ in $48-72 \mathrm{~h}$; Kitabatake 2002; Schumacher et al. 2011; Bosart et al. 2012). The heavy precipitation over Japan after the ET of Etau (2015), mentioned in the introduction, was superimposed on a PRE that developed well poleward of Typhoon Kilo (2015) at about the same time (Kitabatake et al. 2017). Furthermore, PREs may amplify the impact of the transitioning cyclone. The precipitation of the cyclone may impact the same regions that were affected by a PRE earlier, leading to exceptional flooding [recurrence frequency of 2000 years for the ET of Hurricane Erin (2007); Schumacher et al. 2011]. For Australia, a distinct impact has been observed. Enhanced ridge building over southeastern Australia due to PREs associated with recurving TCs at the Australian west coast can be important in the formation of heat waves, which in turn may favor bushfires (section 3b; Parker et al. 2013, 2014).

In summary, the poleward advection of tropical air masses prior to the actual ET may result in a preconditioning of the midlatitude flow, which may strongly impact the final outcome of the transition. Latent heat release and the associated upper-tropospheric divergent flow during extratropical cyclogenesis, the development of diabatic Rossby waves, or the formation of PREs may support the amplification of the upstream midlatitude trough and the first downstream ridge prior to ET.

\section{Downstream impacts}

The amplification of the first downstream ridgetrough couplet due to the processes elaborated in section 2 marks the initiation or modification of a midlatitude RWP (Fig. 1a; red contour). J2003 proposed that ET may excite Rossby waves on the uppertropospheric PV gradient, which will disperse downstream by the mechanisms for downstream development of unstable baroclinic waves (Simmons and Hoskins 1979). Further, J2003 noted the importance of downstream development in the context of forecasting. The main focus of J2003 was on the amplification of the ridge-trough couplet directly downstream of ET. More recent work has investigated the processes that determine downstream development following the onset of ET beyond one wavelength [see Fig. 2 and blue labels for orientation; section 3a(1)] and identified a climatological signal of RWP development downstream of ET [section 3a(2)]. Furthermore, the development of highimpact weather in regions downstream of ET has been investigated more recently (section $3 b$ ).

\section{a. Modification of midlatitude Rossby wave packets}

\section{1) Processes LeAding to MOdificAtion of ROSSBY WAVE PACKETS}

The impact of ET is transmitted farther downstream by modifying the dispersion of RWPs (Riemer et al. 2008; 
Harr and Dea 2009; Riemer and Jones 2010, 2014; Grams et al. 2013b; Pantillon et al. 2013a; Griffin and Bosart 2014; Keller et al. 2014; Riemer et al. 2014; Archambault et al. 2015; Grams and Archambault 2016; Pryles and Ritchie 2016; Quinting and Jones 2016; Keller 2017). The concept of downstream baroclinic development (Orlanski and Sheldon 1995), introduced in section 2a, provides a succinct framework to describe this downstream propagation of the ET's impact (Harr and Dea 2009; Keller et al. 2014; Keller 2017). The initial transmission of $K_{e}$ from the transitioning cyclone into the $K_{e}$ in the western flank of the first downstream ridge by ageostrophic geopotential fluxes and advection (referred to as total $K_{e}$ flux) marks the initiation of downstream baroclinic development. Originating from this $K_{e}$ maximum in the western flank of the trough, diverging and converging ageostrophic geopotential fluxes (Figs. 4a, 9a) and advection result in a total flux of $K_{e}$ that is directed into downstream regions (Fig. 9b), leading to the further amplification of the RWP and its eastward propagation by group velocity. Baroclinic conversion in the remnants of the transitioning cyclone and along the baroclinic zone near the $K_{e}$ maximum in the western flank, as well as in the downstream $K_{e}$ maxima (Fig. 9c) and in possible downstream cyclones, further feed into the ongoing downstream baroclinic development (Orlanski and Sheldon 1995; Wirth et al. 2018).

Consistent with this notion, the ET's downstream impact is also sensitive to the evolution of cyclones in the downstream region (downstream cyclones; Fig. 2), which are main contributors to baroclinic conversion. Hence, a larger Rossby wave amplification near ET does not necessarily lead to a more amplified RWP farther downstream (Riemer and Jones 2010; Pantillon et al. 2015). In other words, the feedback by downstream cyclone development-including the associated moist processes (discussed below)-renders the impact of ET on the downstream region highly nonlinear. Often, however, the generation or amplification of RWPs near ET provides conditions conducive for downstream cyclone development (Hoskins and Berrisford 1988; Agustí-Panareda et al. 2004, 2005; Riemer et al. 2008; Riemer and Jones 2010; Grams et al. 2013b; Pantillon et al. 2013b; Archambault et al. 2015; Grams and Archambault 2016) such that cyclone development tends to be faster and stronger, thereby contributing to the amplification of RWPs downstream of ET.

The downstream impact is sensitive to characteristics of the midlatitude flow. For instance, the generation of midlatitude RWPs, in general, depends on the configuration of the midlatitude flow itself (Röthlisberger et al. 2016, 2018). An initially weaker upper-tropospheric midlatitude jet is typically susceptible to a stronger meridional deflection during ET than a strong jet and results in a more amplified RWP (Riemer et al. 2008;
Riboldi et al. 2018). This is because phase locking is more likely to be achieved with a weak jet, and thus the initial ridge building is more pronounced [section $2 b(1)$ ]. In contrast, a strong jet immediately advects the anticyclonic PV air associated with the transitioning TC's outflow downstream and thus hinders ridge building and phase locking [see Riboldi et al. (2018) for a detailed discussion].

The downstream development associated with ET is also sensitive to moisture transport within the midlatitude flow (Riemer et al. 2008; Grams and Archambault 2016; Riboldi et al. 2018) in accordance with general Rossby wave dynamics (e.g., Gutowski et al. 1992; Teubler and Riemer 2016). Moisture transport toward the baroclinic zone by downstream cyclones, the accompanying latent heat release in ascending moist air masses, and the associated upper-tropospheric divergent outflow result in enhanced ridge building (similar to processes described in section 2a; Riemer et al. 2008; Grams and Archambault 2016). Increased availability of moisture in the downstream region therefore tends to increase the downstream impact of cyclones undergoing ET.

The sensitivity of downstream development during ET to jet configuration and midlatitude moisture dominates over the sensitivity to the initial size and intensity of the transitioning cyclone during its tropical stage. Hence, the downstream impact of ET is-climatologically speaking-relatively insensitive to the intensity and size of the transitioning cyclone during its tropical stage (Archambault et al. 2013; Quinting and Jones 2016; Riboldi et al. 2018). In the case of a midlatitude flow configuration that promotes RWP amplification (i.e., an initially relatively weak upper-tropospheric jet stream and the availability of low-level moisture), however, sensitivity of the downstream impact of ET to the characteristics of the transitioning cyclone emerges: initially stronger TCs often lead to more amplified RWPs (Riemer et al. 2008; Riemer and Jones 2010; Archambault et al. 2013, 2015; Grams and Archambault 2016). Furthermore, transitioning cyclones that reintensify more strongly during ET are associated with more amplified downstream RWPs (e.g., Archambault et al. 2013). Likewise, the strength and duration of baroclinic conversion of $K_{e}$ within the transitioning cyclone determine the amount of additional $K_{e}$ released by the transitioning cyclone that feeds the development of the RWP (Harr and Dea 2009; Keller et al. 2014; Keller 2017).

Favorable phasing is a prerequisite for the initiation of substantial downstream development [see section $2 b(2)$ ]. When favorable phasing occurs, the strength of the interaction between the midlatitude flow and the transitioning cyclone influences downstream development 

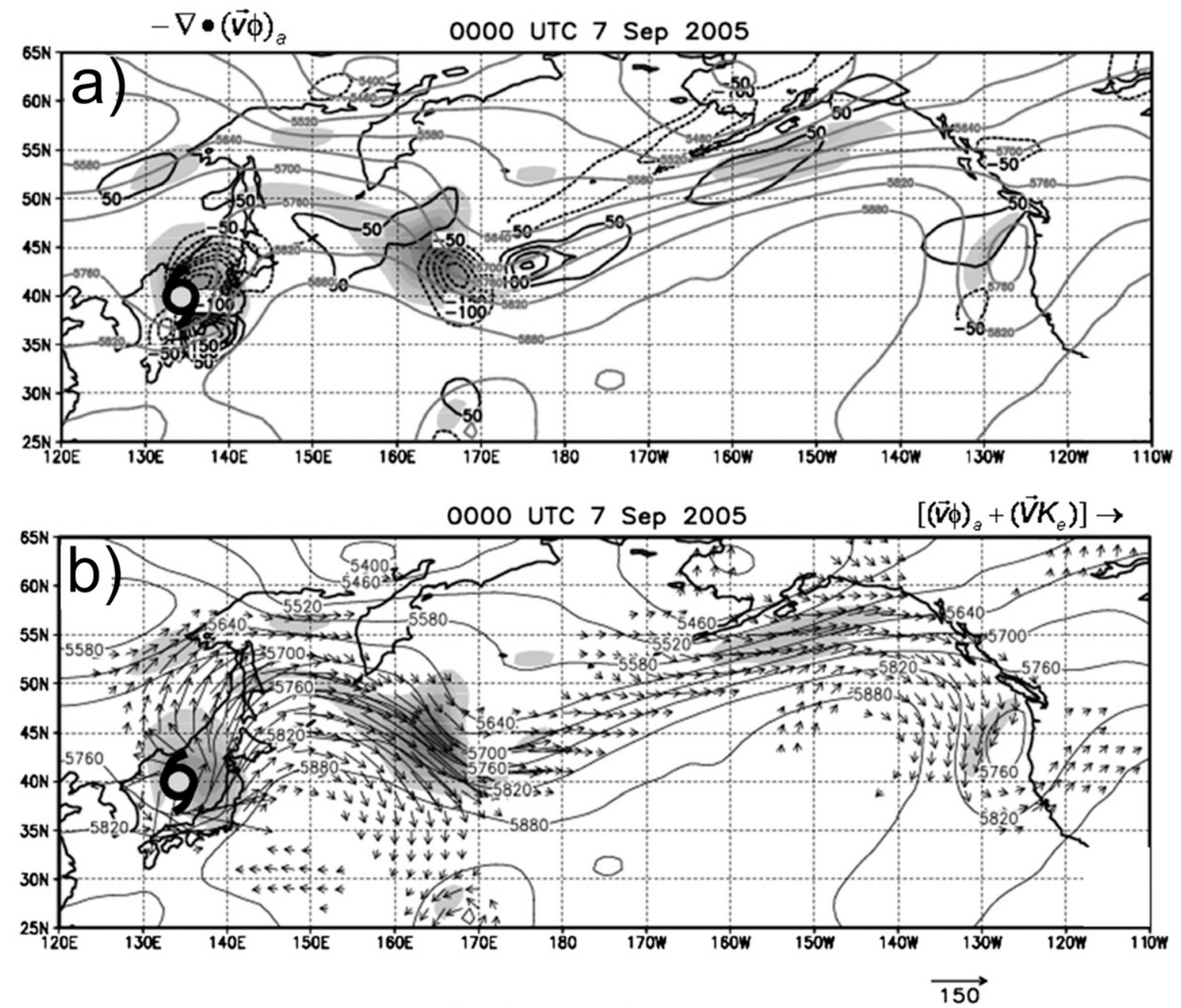

- $\omega \alpha$

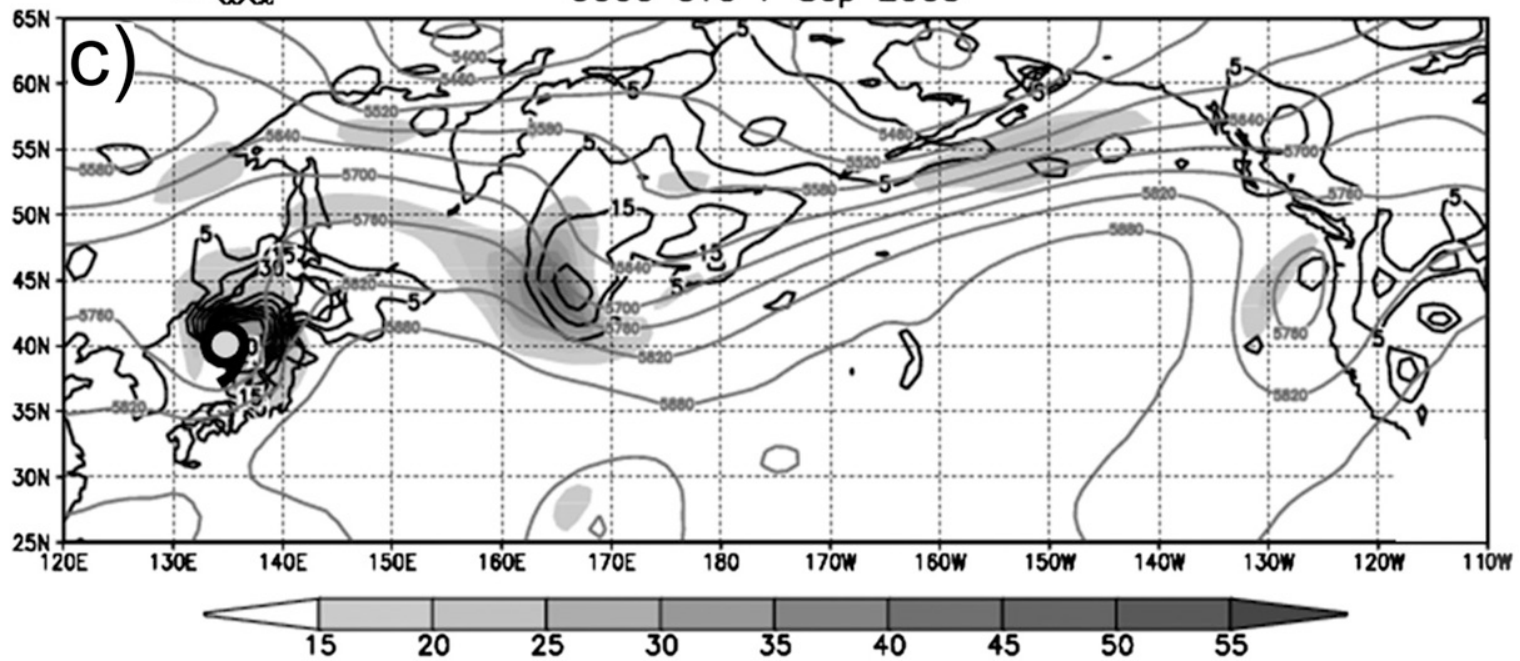

FIG. 9. Downstream development during the ET of Typhoon Nabi (2005). Vertically integrated $K_{e}$ (shaded; $10^{5} \mathrm{~J} \mathrm{~m}^{-2}$ ) and $500-\mathrm{hPa}$ heights (light gray contours; 60-m intervals) and (a) vertically integrated divergence (dashed) and convergence (solid) of the ageostrophic geopotential flux (contours; $\mathrm{W} \mathrm{m}^{-2}$ ); (b) vertically integrated total $K_{e}$ flux vectors (advection + dispersion; reference vector in lower right; $10^{5} \mathrm{~W} \mathrm{~m}^{-1}$ ); and (c) vertically integrated baroclinic conversion (contours; $\mathrm{W} \mathrm{m}^{-2}$ ). [Figures 3a-c from Harr and Dea (2009).] 
during ET, with strong interactions leading to more amplified RWPs than weak interactions. The strength of the interaction (i.e., interaction metric) can be approximately quantified by the upper-tropospheric advection of anticyclonic PV by the divergent outflow (Archambault et al. 2013). The divergent outflow (Fig. 10a) advects anticyclonic PV poleward (upper panel in Fig. 10a) and thereby enhances the PV gradient and deflects the jet stream, which results in jet streak formation (lower panel in Fig. 10a). Although the jet and the PV gradient might be initially weak, for western North Pacific strong interactions, a pronounced jet streak and downstream ridge evolve (Fig. 10b), whereas the jet remains weak and is less deflected poleward with weak interactions (Fig. 10c). Strong interactions typically lead to more amplified RWPs that reach North America (Fig. 10d), as compared to weak interactions (Fig. 10e), for which RWPs dissipate well prior to reaching North America (not shown). The interaction metric is in line with the more general concept that anticyclonic vorticity advection by the divergent wind acts as a Rossby wave source (Sardeshmukh and Hoskins 1988; Hodyss and Hendricks 2010).

The abovementioned processes facilitate the amplification of RWPs and thus downstream development during ET. In cases where the transitioning cyclone interacts with an already-well-amplified midlatitude RWP, ET may initiate Rossby wave breaking and can thus be detrimental to downstream development (Riemer and Jones 2014).

\section{2) A Climatological PeRsPective on RWP AMPLIFICATION DURING ET}

Despite the large case-to-case variability and nonlinear interactions of the processes that govern the downstream development initiated by ET, RWP amplification downstream of ET reveals itself as a climatologically consistent feature in most ocean basins.

In the western North Pacific and south Indian Ocean, RWPs downstream of ET are more amplified and occur more frequently than in climatology. They are also more amplified than RWPs associated with extratropical cyclones (Torn and Hakim 2015, Quinting and Jones 2016). Between June and November, an enhancement of RWP frequency by up to $15 \%$ (Fig. 11a) becomes apparent downstream of ET across the western and central North Pacific, as well as North America. For the same period, the south Indian Ocean RWP frequency is enhanced by up to $18 \%$ (Fig. 11b).

The impact of ET on RWPs in the North Atlantic is less clear. Compared to RWPs associated with extratropical cyclones, the RWPs downstream of ET in the North Atlantic appear to be less amplified (Torn and Hakim 2015). Compared to climatology, however,
RWPs downstream of ET do not show significant differences in their amplitude (Quinting and Jones 2016). These different results found for the North Atlantic basin might stem from differences in the methods of these studies to detect RWPs and from the different sample sizes. Furthermore, the lack of statistically significant differences from climatology in the amplification of RWPs downstream of North Atlantic ET might result from the sensitivity to the midlatitude jet structure. The North Atlantic jet is climatologically short and weak and thus prone to stronger amplification, but also to wave breaking, which may disrupt downstream development (Wirth et al. 2018). The climatological results are confirmed by case studies for the North Atlantic, which were not able to unambiguously attribute RWP amplification in the North Atlantic to ET (e.g., AgustíPanareda et al. 2004; McTaggart-Cowan et al. 2001, 2003, 2004; Grams et al. 2011; Pantillon et al. 2015).

In summary, the downstream impact of ET can be interpreted as the local modification of RWPs that then disperse this impact downstream. RWP amplification is more likely if the midlatitude upper-tropospheric jet is initially relatively weak and enhanced low-level moisture is available. In such a midlatitude flow susceptible to RWP amplification, and if the transitioning cyclone is in favorable phasing with an upstream trough, cyclone characteristics such as intensity and/or strength of the TC-midlatitude flow interaction further modulate the downstream impact of ET. The downstream impact of ET manifests as a climatologically consistent signal in RWP amplification downstream of the transitioning cyclone in the western North Pacific and south Indian Ocean, whereas the climatological signal in the North Atlantic might be masked by Rossby wave breaking initiated during ET.

\section{b. Downstream high-impact weather}

By triggering or amplifying midlatitude RWPs, ET may contribute to the development of high-impact weather in downstream regions (e.g., Harr and Archambault 2016). The relationship between ET and downstream highimpact weather exists because strongly amplified RWPs, in general, may result in blocking anticyclones (e.g., Nakamura et al. 1997; Renwick and Revell 1999; Martius et al. 2013; Riboldi et al. 2019), establish atmospheric conditions that are prone to strong cyclogenesis (e.g., Hoskins and Berrisford 1988), or favor PV streamers and associated heavy precipitation (e.g., Martius et al. 2008). To date, the influence of ET on high-impact weather in downstream regions, mediated by RWPs, has been investigated via case studies. The findings of these case studies are presented here for each ocean basin, but more research is needed to generalize and quantify this 

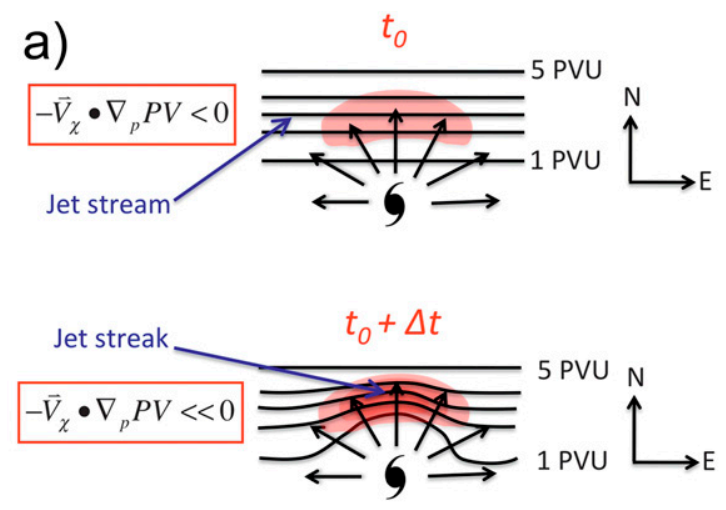

b) Strong interactions

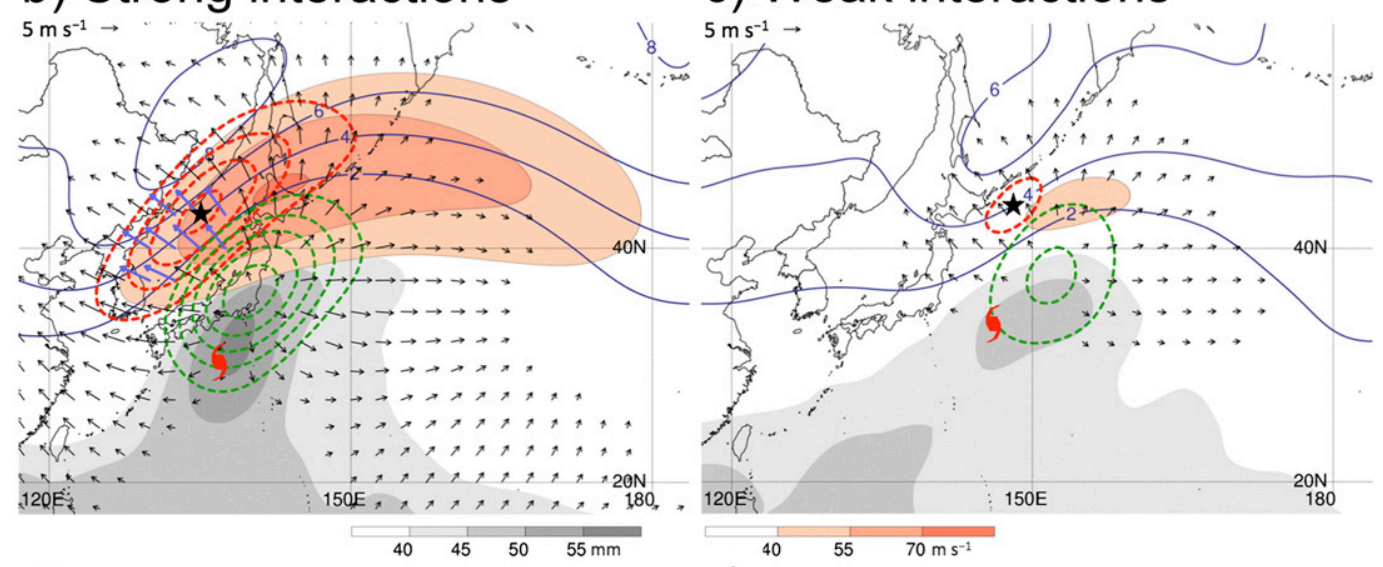

d)

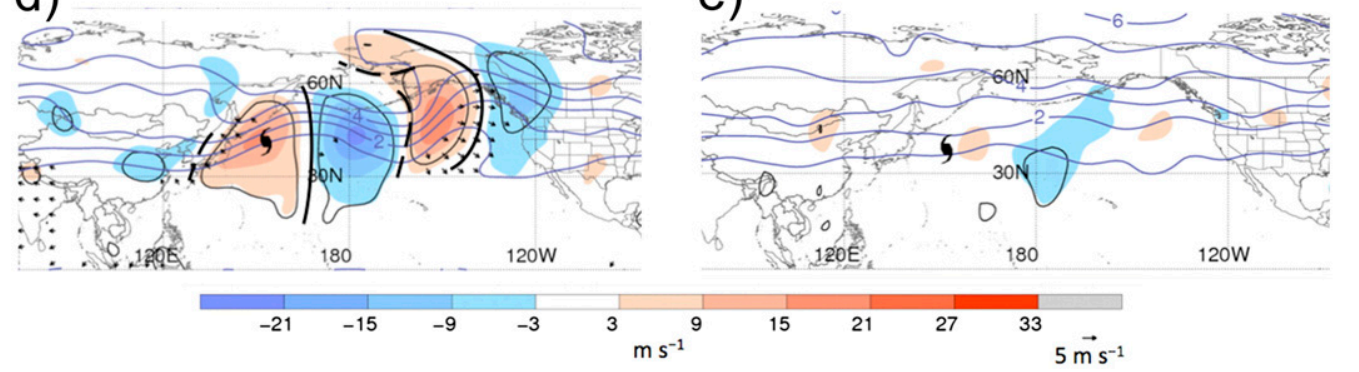

FIG. 10. Interaction between a transitioning cyclone and the midlatitude flow expressed as advection of low PV air by the upper-level divergent outflow. (a) Idealized representation of ridge amplification and jet streak intensification. Vectors represent the upper-tropospheric divergent outflow associated with the transitioning cyclone. Shading denotes anticyclonic PV advection by the divergent wind (Archambault et al. 2013, their Fig. 4). Composite analyses of objectively defined (b) strong and (c) weak interactions at the time of maximum interaction. The 500-hPa ascent (green; every $2 \times 10^{-3} \mathrm{hPa} \mathrm{s}^{-1}$, negative values only), total column precipitable water (shaded according to grayscale; $\mathrm{mm}$ ), 200-hPa PV (blue; every 1 PVU), irrotational wind (vectors, $>2 \mathrm{~m} \mathrm{~s}^{-1}$; purple vectors, $>8 \mathrm{~m} \mathrm{~s}^{-1}$ ), negative PV advection by the irrotational wind (dashed red; every 2 PVU day ${ }^{-1}$ starting at -2 PVU day ${ }^{-1}$ ), and total wind speed (shaded according to color bar; $\mathrm{m} \mathrm{s}^{-1}$ ). The star denotes point of maximum interaction. The TC symbol denotes composite TC position. Downstream development of (d) strong and (e) weak interactions $36 \mathrm{~h}$ after time of maximum interaction as represented by 250 -hPa meridional wind anomalies (shaded; $\mathrm{m} \mathrm{s}^{-1}$; enclosed by black contours where significant at the $99 \%$ confidence level), PV (blue; every 1 PVU), and irrotational wind (vectors; $>2 \mathrm{~m} \mathrm{~s}^{-1}$ ). [Figures 8a,b, 5d, and 6d from Archambault et al. (2015).]

aspect of the ET's downstream impact and to improve the predictive capabilities for such events.

An enhanced frequency of blocking anticyclones downstream of ET has been reported for the south
Indian Ocean and the western North Pacific region (Riboldi et al. 2019). Over the south Indian Ocean, such blocking anticyclones are, in general, a prerequisite for the formation of southeast Australian heat waves 

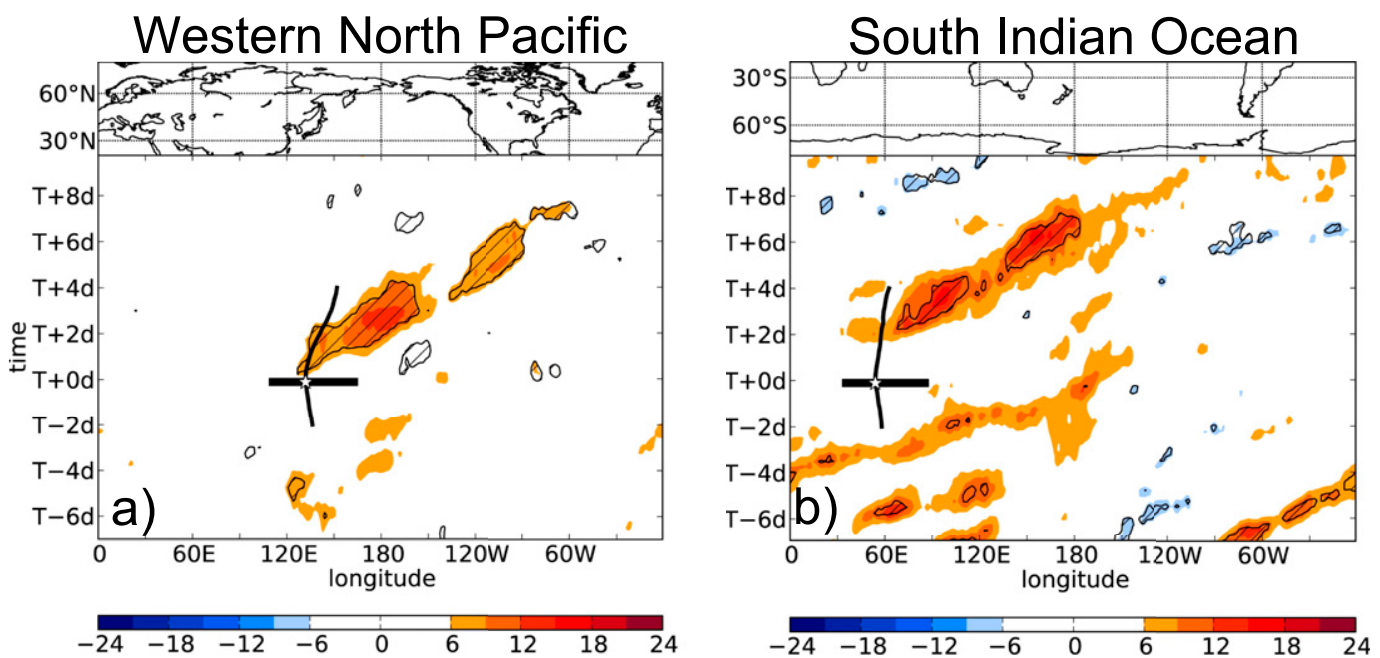

FIG. 11. Recurvature-relative composites of enhanced RWP frequency anomaly (shaded in \%) (a) relative to June-November climatology for western North Pacific transitioning cyclones and (b) relative to December-April climatology for south Indian Ocean transitioning cyclones. Statistical significance at $95 \%$ confidence level hatched, mean track given by black line. Mean and range of recurvature longitudes indicated by white star and black bar, respectively. Data smoothed with a Gaussian filter. [Figures 3a and 5a from Quinting and Jones (2016).]

(Quinting and Reeder 2017). The "pre-Black Saturday heat wave" in 2009 caused devastating bushfires in southeast Australia and is a prominent example, in which ET crucially affected the amplification of the blocking anticyclone (Parker et al. 2013, 2014).

In the western North Pacific region, blocking anticyclones that result from the amplification of the RWP during ET are suggested by Small et al. (2014) to be linked to the peak in blocking frequency, found for September and October in the North Pacific. Such blocking anticyclones have been associated with heat waves across western North America and cold-air outbreaks and heavy precipitation in central and eastern North America (Grams 2011; Keller and Grams 2015; Bosart et al. 2015; Harr and Archambault 2016). An example of such a development is the extratropical reintensification of Supertyphoon Nuri (2014). The midlatitude flow amplification during Nuri's ET (cf. Fig. 1) resulted in the formation of a major omega block along the west coast of North America (Fig. 12a) and several cold-air outbreaks over continental North America (Bosart et al. 2015). A similar pattern has been found for Typhoon Choi-Wan (2009), for which it could be shown that ET did alter the location and severity of the heat wave, cold-air outbreak, and heavy precipitation, whereas these events occurred in other places and to a weaker extent in an NWP experiment in which the respective TCs had been removed (Fig. 12b; Keller and Grams 2015). In addition to the formation of blocking anticyclones in the eastern North Pacific, ETs in the western North Pacific might contribute to the formation of
Kona lows, which may bring flash floods, high winds, and thunderstorms to Hawaii (Moore et al. 2008).

In the North Atlantic, several studies have documented that the amplification of the first downstream ridge results in wave breaking and the formation of PV streamers and cutoff lows over Europe (McTaggartCowan et al. 2007; Grams et al. 2011; Pantillon et al. 2013a; Grams and Blumer 2015; Pantillon et al. 2015). These PV streamers and cutoff lows over Europe may affect the development of severe thunderstorms and heavy precipitation (Pantillon et al. 2015; Grams and Blumer 2015), the formation of Mediterranean cyclones (Pinto et al. 2001; Grams et al. 2011; Chaboureau et al. 2012; Pantillon et al. 2013a), or the track and intensity of extratropical cyclones in the region (Agustí-Panareda et al. 2004; Hardy et al. 2017a,b) and associated heavy precipitation (Kumpf et al. 2019). Furthermore, the PV streamers may also influence the development of subsequent North Atlantic hurricanes (Galarneau et al. 2015).

\section{Predictability}

J2003 highlighted the often basin-wide reduction in NWP skill that may accompany ET. During ET, forecasters thus face the challenge to predict potential downstream high-impact weather while forecast uncertainty is enhanced (purple labels and semitransparent shading in Fig. 2). As sources for the increased forecast uncertainty, J2003 discussed shortcomings of NWP models in the representation of moist 

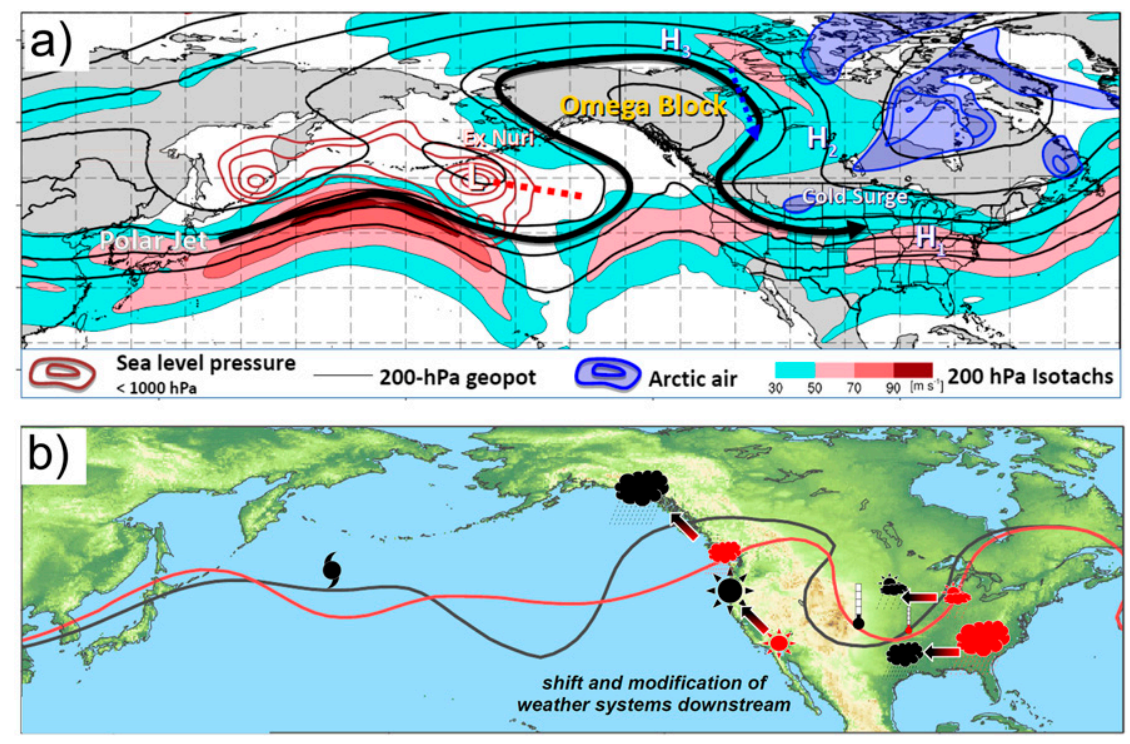

FIG. 12. (a) Illustration of omega block and high-impact weather downstream of Typhoon Nuri (2014) after Bosart et al. (2015). (b) Downstream impact of Typhoon Choi-Wan (2009), based on NWP experiments where the storm has been removed from initial conditions (Keller and Grams 2015). Black items represent midlatitude flow features in the presence of ET, and red items the evolution if ET influences were not present: $300-\mathrm{hPa}$ geopotential height contour indicates upper-level waveguide (950 dam at 0000 UTC 22 Sep 2009). Arrows indicate shift of high-impact weather (precipitation, sunny and hot conditions, cold conditions) with symbol size representing magnitude.

processes and in capturing the interaction between the small-scale TC and the large-scale midlatitude flow. The recent findings on the important contribution of the upper-tropospheric divergent outflow to initial ridge amplification, the sensitivity to phasing between the recurving TC and the upstream trough, and the existence of the bifurcation point near the tip of the upstream trough support these shortcomings identified by J2003. In this section, we discuss the now-better understanding of the general intrinsic uncertainty associated with ET and of how the processes involved in ET impact forecast quality, both near the transitioning cyclone and in downstream regions (sections $4 \mathrm{a}, 4 \mathrm{~b}$ ). Furthermore, we discuss the contribution of observations to improve prediction during ET (section 4c).

\section{a. Causes for forecast degradation in downstream regions during ET}

\section{1) INTERACTION WITH THE MIDLATITUDE FLOW AND PHASING}

An incorrect representation of the phasing between the transitioning cyclone and the upstream midlatitude trough in a forecast may lead to large position and intensity errors for both the cyclone and the emerging midlatitude RWP (J2003). Thus, forecasts for ET are particularly sensitive to the representation of the upstream midlatitude trough and the transitioning cyclone (Kim and Jung 2009; Torn and Hakim 2009; Anwender et al. 2010; Doyle et al. 2011; Pantillon et al. 2013b). As an example of this sensitivity, consider a forecast initialized during the recurvature of Typhoon Shanshan (2006; Fig. 13). Singular vector sensitivities pick up the transitioning cyclone, as well as the approaching upstream trough, indicating that strongest error growth will be tied to the development of these two flow features (Reynolds et al. 2009; Wu et al. 2009). The sensitivity to the upstream midlatitude trough may become more dominant during and after recurvature of the transitioning cyclone (Kim and Jung 2009).

The existence of the bifurcation point near the tip of the upstream trough (Fig. 6) explains these sensitivities: small differences on the order of $100 \mathrm{~km}$ in the TC track can determine whether the cyclone starts to recurve in the trough-relative framework and undergoes reintensification with potential downstream impact or if it decays (e.g., Grams et al. 2013b; Komaromi and Doyle 2018). Given that a track error of $100 \mathrm{~km}$ is quite typical in 48 -h forecasts over recent years (Lang et al. 2012a; NHC 2017), the trough-cyclone phasing can thus be a substantial source for forecast errors.

\section{2) DiAbATIC PROCESSES}

Another key source of forecast uncertainty is the representation of diabatic processes in NWP models. 


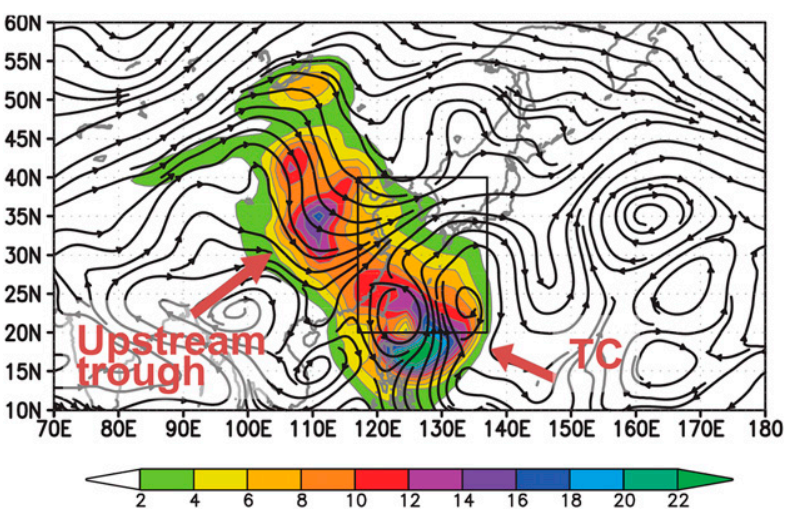

FIG. 13. Vertically integrated initial-time dry total energy singular vector sensitivities (shaded; values in color bar: $\mathrm{J} \mathrm{kg}^{-1}$ ) with 500-hPa streamlines for TC Shanshan from 0000 UTC 15 Sep 2006. [Figure 3c from Reynolds et al. (2009).]

The convective parameterization schemes employed in all global models, and in some regional models, might underrepresent divergent outflow aloft, in part because the divergent outflow is a gridscale response to resolved precipitation processes, as well as parameterized convective heating and moistening (Zadra et al. 2018). This error in the representation of diabatic processes affects the correct simulation of initial ridge amplification and RWP generation.

The importance of considering moist processes for predicting the midlatitude impact of ET is corroborated from a singular vector perspective. Ensemble spread is significantly larger in ET forecasts, for which the initial perturbations are obtained from moist singular vectors ${ }^{4}$ (Buizza et al. 1993), as compared to ensemble forecasts constructed from dry singular vectors (Lang et al. 2012b). This corroborates the importance of considering moist processes for predicting the midlatitude impact of ET. An increased ensemble spread is found both near the transitioning cyclone and in downstream regions. Similar results are found for increasing the horizontal resolution at which the singular vectors are calculated from about 200 to $80 \mathrm{~km}$.

Another factor that affects perturbation growth in ensemble forecasts (assessed through singular vectors and adjoints) is the baroclinicity of the midlatitude flow into which the transitioning cyclone is moving, with stronger baroclinicity supporting stronger error growth (Reynolds et al. 2009; Doyle et al. 2011). Furthermore, the use of explicit convection may improve the forecasted cyclone track and phasing, compared to a simulation with parameterized

\footnotetext{
${ }^{4}$ Meaning that moist processes are considered when determining those flow features that are affected by strongest perturbation growth
}

convection (Pantillon et al. 2013a). In that study, however, this effect results from differences between explicit and parameterized convection along the associated RWP rather than from improvements in the core of the transitioning cyclone. A strong sensitivity to moisture and diabatic processes has also been found in previous studies (Riemer et al. 2008; Doyle et al. 2012; Grams and Archambault 2016), which further underscores the importance of diabatic processes and associated rapid error growth downstream of ET events (e.g., Harr and Dea 2009; Hodyss and Hendricks 2010; Torn 2010, 2017; Archambault et al. 2015).

Research on the representation of diabatic processes in numerical models in the context of ET has been limited to date. Investigations do exist, however, for the representation of diabatic processes in extratropical cyclones (e.g., Davis et al. 1993; Stoelinga 1996). More recently, diabatic processes associated with mesoscale convective systems and warm conveyor belts have been studied in the context of error growth. Since these systems likewise modify RWPs by their upper-tropospheric divergent outflow, it can be assumed that the findings of these investigations also hold true during ET.

The representation of diabatic processes associated with mesoscale convective systems over the Great Plains has been identified as a source of short-term skill degradations (busts) in ECMWF forecasts for Europe (Rodwell et al. 2013). In such cases, diabatic processes act to decelerate the eastward progression of a synopticscale trough over the Rocky Mountains, similar to the processes described in section $2 \mathrm{~b}$. Errors in the representation of these diabatic processes and their impact on the midlatitude flow may lead to large phase errors in the representation of the downstream RWP. Another contribution to ECMWF forecast errors stems from the representation of warm conveyor belt outflow. Substantial differences in PV generation, depending on the microphysical parameterization used, may lead to variations in warm conveyor belt development and different positions of its outflow (Joos and Wernli 2012; Joos and Forbes 2016). In addition, as warm conveyor belt outflow is sensitive to environmental conditions, warm conveyor belt activity can amplify initial condition error and project it on the large-scale circulation (e.g., Grams et al. 2018). These differences in the outflow position and the associated tropopause structure translate into differences in the midlatitude RWP and hence the synoptic development in downstream regions (e.g., Dirren et al. 2003; Davies and Didone 2013; Joos and Forbes 2016; Lamberson et al. 2016; Baumgart et al. 2018).

In summary, the skill of predicting the impact of a transitioning cyclone on the midlatitude flow depends on the representation of the cyclone and the environmental features, as well as their phasing. The ability of 
NWP models to properly forecast these flow features and their phasing and interaction is, to a large extent, determined by the representation of diabatic processes in the model. Small deviations in the simulation of these processes may lead to a slightly different representation of these flow features, a positioning error, for example. Such an error may amplify rapidly due to the prevalence of a bifurcation point in the steering flow and can lead to large forecast errors in downstream regions.

\section{b. Manifestation of midlatitude forecast uncertainty during ET}

The decrease in forecast skill downstream of ET events was documented by J2003 (their Fig. 8) as a drop in the anomaly correlation for forecasts over the North Pacific. More recent research has focused on investigating and characterizing the manifestation of this forecast uncertainty, in particular in ensemble prediction systems.

Because of forecast uncertainty associated with the direct and downstream impact of ET, ensemble standard deviation is typically increased downstream of the transitioning cyclone (Fig. 14). A first increase is found at the onset of interaction between the transitioning cyclone and the midlatitude flow in the direct vicinity of the cyclone, as also discussed in section $6 \mathrm{c}$ of Part I (e.g., McTaggart-Cowan et al. 2006a; Munsell and Zhang 2014; Pantillon et al. 2016; Torn et al. 2015). With increasing forecast lead time, the standard deviation increases and spreads farther downstream, often linked to the predicted position of the transitioning cyclone. The increase in standard deviations varies for different ensemble prediction systems (Fig. 14), due to differences in ensemble size, generation of initial conditions, and the different capabilities of models in simulating the processes associated with ET (Harr et al. 2008; Anwender et al. 2008; Keller et al. 2011). Identifying which of the models in Fig. 14 performs best in predicting the forecast uncertainty associated with ET, hence, produces the best match between ensemble standard deviation and ensemble mean RMS error, would require an investigation over many ET cases, and has not been addressed yet.

The increase in standard deviation is connected to the development of several forecast scenarios across the members of one ensemble forecast, which can be revealed through a cluster analysis. Besides providing information about the possible synoptic development for forecasting purposes, these different forecast scenarios provide a means to study the underlying physical and dynamic processes responsible for the different scenarios (Anwender et al. 2008; Harr et al. 2008; Keller et al. 2011, 2014; Kowaleski and Evans 2016).
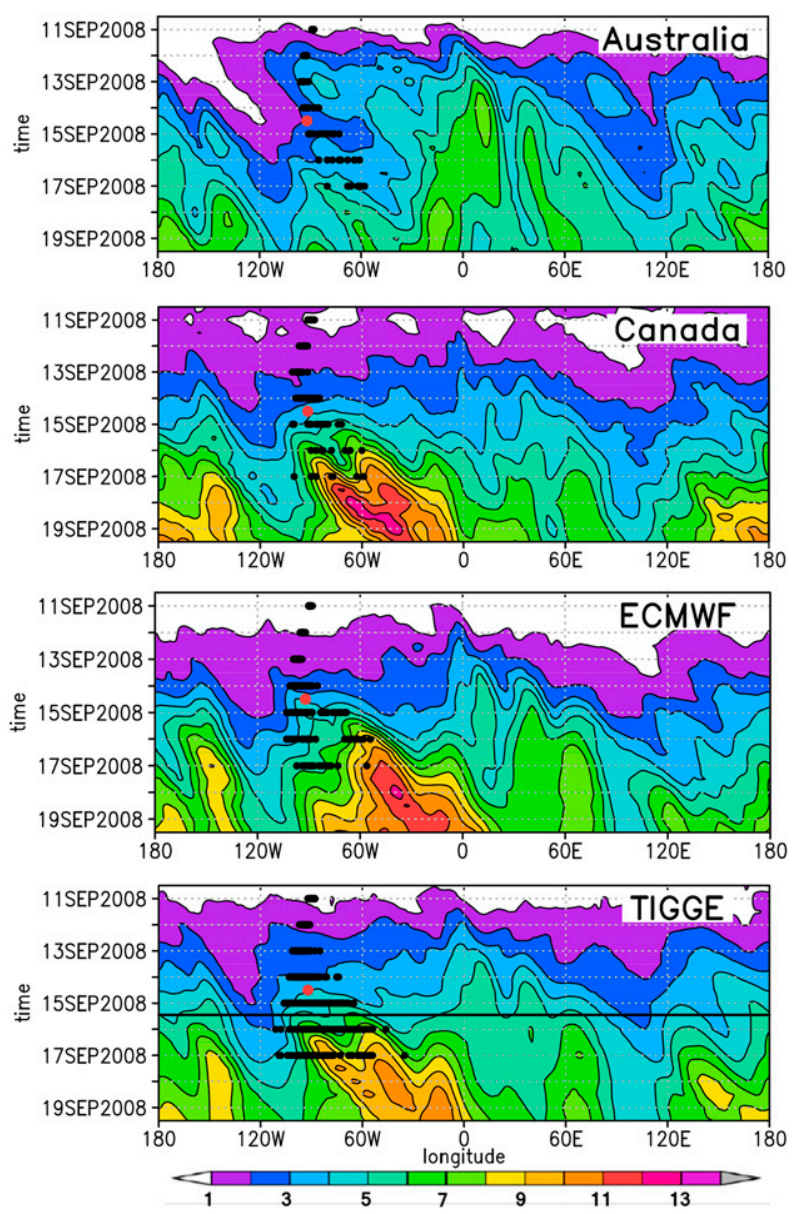

FIG. 14. Increase in standard deviation of the $500-\mathrm{hPa}$ geopotential height (in dam) in the Australian, the Canadian, the ECMWF, and the TIGGE (Swinbank et al. 2016) multimodel EPS for the ET of Hurricane Ike. Forecast initialized 0000 UTC 10 Sep 2008. TC position in ensemble members is marked by the black dots, best track position at ET time by the red dot. [Figure 1 from Keller et al. (2011).]

Differences in phasing and the representation of diabatic processes affect the predicted amplification of the first downstream ridge. Hence, the largest differences in an ensemble forecast are usually found in the crest and/or flanks of the first downstream ridge, as depicted in Fig. 15 (e.g., Anwender et al. 2008; Harr et al. 2008; Keller et al. 2011, 2014; Pantillon et al. 2016). This example has been derived from an empirical orthogonal function analysis (EOF; e.g., Wilks 2011) applied to an ECMWF ensemble forecast for the potential temperature at the tropopause. The strongest variability among the ensemble members, described by the EOFs, is found in the flanks of the ridge (left; Figs. 15a,c) and the crests of the ridge-trough couplet (right; Figs. 15a, c). Higher potential temperature is found in the region of positive EOF signals (and lower potential temperature in regions of negative EOF signals) for ensemble members 
a)

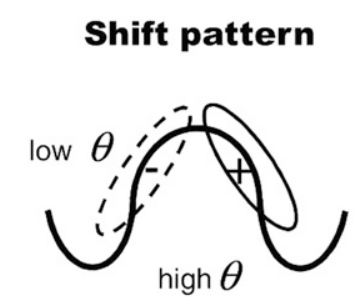

N

Amplitude pattern

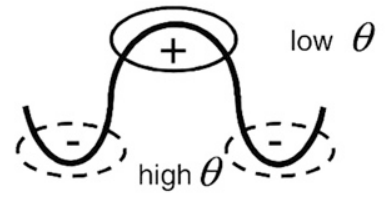

S

\section{b)}

pos.

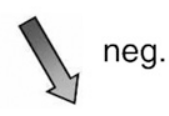
neg.

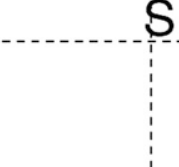

s
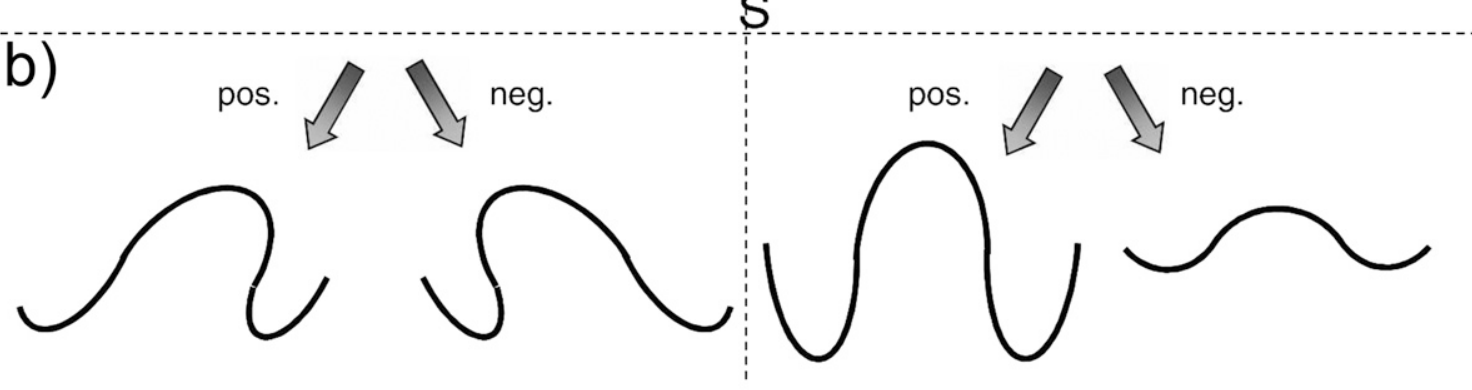

neg.

C)
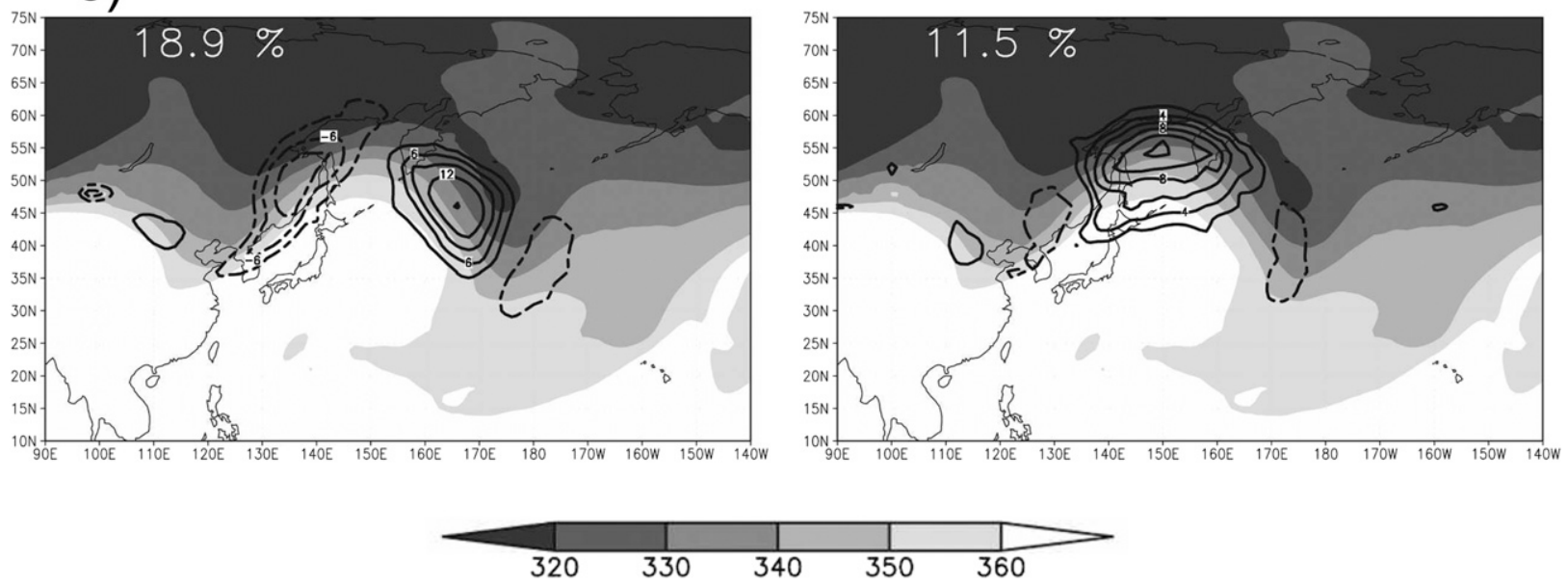

FIG. 15. (a) Schematic of the shift and amplitude pattern of ensemble forecast uncertainty derived from the first two EOFs (thin solid and dashed lines) of potential temperature on the dynamical tropopause in ensemble members. The thick black line represents the strong potential temperature gradient on the dynamic tropopause in the midlatitudes. (b) Synoptic patterns (shape of ridge) that result from the contribution to the variability patterns. (c) EOF 1 (left; contours) and 2 (right; contours) for potential temperature at 2 PVU (shaded in K) in an ECMWF ensemble forecast for Typhoon Maemi (2003). Values indicate percentage of total uncertainty captured by the respective EOF. [Figures 9, 10a, and 10b from Anwender et al. (2008).]

that contribute positively to these EOF patterns. This leads to an eastward tilt or shift in the downstream ridge and a stronger amplification of such members (Fig. 15b), as compared to the ensemble mean. These shift and amplitude patterns (or a combination thereof) associated with the representation of the first downstream ridge have been found in all the studies cited above. Hence, these patterns provide a robust signal on how the forecast variability during ET affects the representation of the first downstream ridge in ensemble forecasts.

Subsequently, the initial uncertainty then propagates farther downstream with the group velocity of the midlatitude RWP in which the uncertainty is embedded (Harr et al. 2008; Anwender et al. 2008, 2010; Pantillon et al. 2013a; Grams et al. 2015). Without the development of an RWP during ET (Quinting and Jones 2016), or for short forecast lead times (Strickler et al. 2016), forecast uncertainty remains limited to the direct vicinity of the transitioning cyclone, corroborating the essential role of the RWP in transmitting forecast uncertainty into downstream regions. In addition to this downstream dispersion of forecast uncertainty, the representation of diabatic processes within potentially developing downstream cyclones may add additional 
uncertainty to the development of the midlatitude RWP downstream of ET.

From a climatological standpoint, a statistically significant increase in forecast uncertainty downstream is noted for western North Pacific, North Atlantic, and south Indian Ocean ET data (Aiyyer 2015; Quinting and Jones 2016; Torn 2017). Forecast uncertainty associated with the downstream wave packet (measured in terms of normalized ensemble spread; Fig. 16) tends to peak about 4-5 days after recurvature (2-3 days after ET) and decreases to average conditions within 5-6 days, with the strongest increase observed in the downstream troughs (Aiyyer 2015). The increase in spread results in a reduction of the forecast skill horizon by about 2 days, mainly tied to the uncertainty in the amplification of the first downstream ridge (Grams et al. 2015). The forecast uncertainty decreases when the forecast is initialized closer to the completion of ET, with the phasing being already developed. This suggests that predictive skill during ET is at least partly an initial value problem (Harr et al. 2008; Anwender et al. 2008).

ET may not only affect midlatitude medium-range forecasts but may even deteriorate the accuracy of subseasonal predictions. Although the transitioning cyclone was included in the initial conditions (10-day average initial conditions), the National Centers for Environmental Prediction Climate Forecast System (NCEP CFSv2) was not able to predict the reconfiguration of the large-scale flow by Typhoon Nuri (Bosart et al. 2015).

In summary, the decrease in forecast skill associated with ET events initially manifests as uncertainty in the prediction of the amplifying first downstream ridge. Subsequently, the forecast uncertainty propagates downstream with the developing RWP, while it may be further increased in the regions affected by developing downstream cyclones.

\section{c. Impact of observations}

As stated earlier, parts of the forecast uncertainty associated with ET might be tied to an insufficient accuracy of initial conditions. J2003 noted that single observations may have a strong influence on predicting ET and its downstream impact. They suggested further investigation on how existing observations can be used in an optimum way and to exploit new observational capabilities. Since J2003 appeared, additional targeted observations (Majumdar 2016) have been gathered in field experiments, such as The Observing System Research and Predictability Experiment (THORPEX; Parsons et al. 2017) Pacific-Asian Regional Campaign 2008 (T-PARC). These additional observations provided more detailed insights in the processes of ET, as well as on the benefit of observations for ET forecasts.
The impact of observations on ET forecasts in the North Atlantic has been tested in data-denial experiments with the ECMWF Integrated Forecast System. In these experiments, observations were removed either in sensitive regions (identified via singular vectors as regions where errors grow most quickly) near ET, in sensitive regions in the midlatitudes, or in randomly chosen regions (Cardinali et al. 2007; Chen and Pan 2010; Anwender et al. 2012). Removal of observations in sensitive regions during an ET event results in forecast degradations that are 6 times larger than degradations produced by removal of observations that are randomly selected (Cardinali et al. 2007; Chen and Pan 2010). Compared to denying data in extratropical sensitive regions (SVout; Fig. 17a), removing observations near ET (ETout; Fig. 17b) led to about the same magnitude of forecast degradation $(87 \%$ vs $83 \%$ of degraded forecasts), measured in terms of the root-meansquare difference for total energy (Anwender et al. 2012). Denying data near the transitioning cyclone is, on average, more impactful than denying data in extratropical sensitive regions for medium-range forecasts (Anwender et al. 2012). This also implies that poorly observed transitioning cyclones yield, on average, larger forecast degradations than unobserved extratropical sensitive regions. After completion of ET, however, larger degradations are associated with denying data in extratropical sensitive regions.

Experiments with dropsonde data, gathered during T-PARC for the ET of Typhoons Sinlaku and Jangmi, corroborate these findings. Observations taken after recurvature toward the completion of ET do not result in significant forecast improvements in the midlatitudes, although the observations were taken in sensitive regions (Weissmann et al. 2011). In contrast, significant forecast improvements, also in the midlatitudes, are found for observations that were taken near the transitioning cyclone earlier in its life cycle. Weissmann et al. (2011) explained this by the fact that observations during early stages of the TC's life cycle are typically taken in datasparse regions, although the western North Pacific midlatitudes have denser observation coverage and are thus better represented in the analysis anyway.

In summary, a number of studies highlight the enhanced sensitivity to initial conditions and increased potential for error growth during ET, both near the transitioning cyclone and in the downstream midlatitudes. Although the results seem to be quite robust, they are mainly based on case studies, and case-to-case variability still needs to be assessed in a systematic manner.

\section{Conclusions and outlook}

The ET of a tropical cyclone may modify the midlatitude flow and result in a basinwide reduction in 


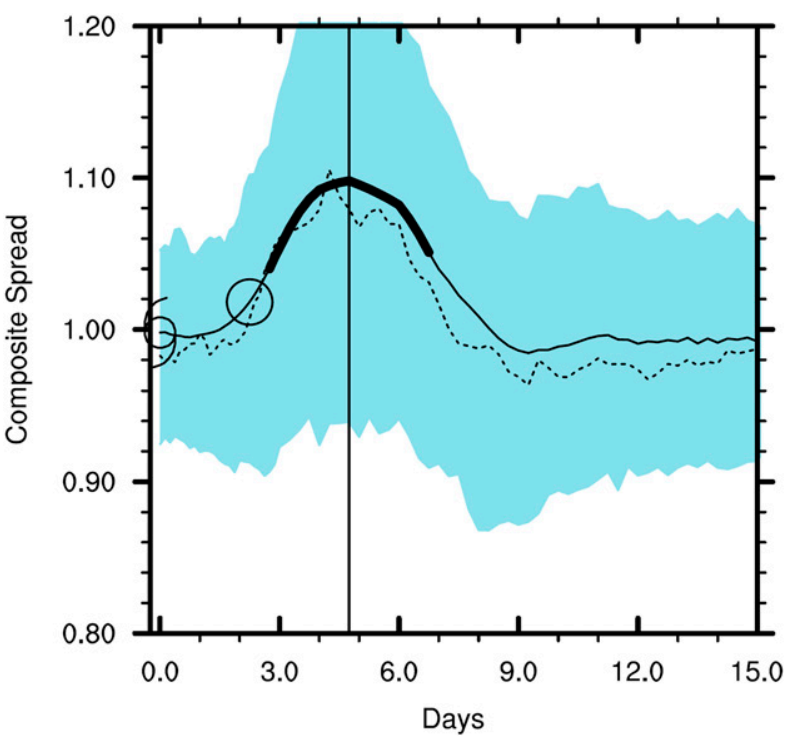

FIG. 16. Normalized ensemble spread of 500-hPa geopotential height as a function of forecast hour for NOAA's second-generation global reforecasts initialized at recurvature time. Data cover all western North Pacific tropical cyclones from 1985 to 2013. Solid line shows the mean, dashed line shows the median, and the shaded region shows the 25th-75th percentile range of the distribution. Statistically significant values of the mean are shown as the thicker line. Hurricane symbol marks the time of recurvature, circle marks the median time of ET, and the thin vertical line marks the peak spread. [Figure 3a from Aiyyer (2015).]

forecast skill of NWP models, as summarized in the review paper by J2003. Since J2003 appeared, the ET research community has worked toward a better understanding of the interaction between a TC and the midlatitude flow. It has been demonstrated that ET impacts the midlatitude flow such that a midlatitude RWP is initiated or amplified. This RWP then spreads the impact of the ET downstream over a large geographical region.

The first stage of this RWP amplification involves enhanced ridge building immediately downstream of the transitioning cyclone, often accompanied by the development of a jet streak, and is considered a direct impact (Fig. 2, red labels; section 2a). The amplification of this ridge is a consequence of the favorable superposition of the dry dynamics of the growing baroclinic wave and the diabatically enhanced upper-tropospheric outflow associated with latent heat release. During the early stage of ET, this latent heat release occurs primarily with the deep convection near the center of the cyclone. Later during ET, the latent heat release that enhances the upper-tropospheric divergent outflow is primarily tied to warm and moist air masses ascending slantwise along the baroclinic zone. These air masses are advected poleward by the cyclonic circulation of the transitioning cyclone and ascend as a warm conveyor belt along the
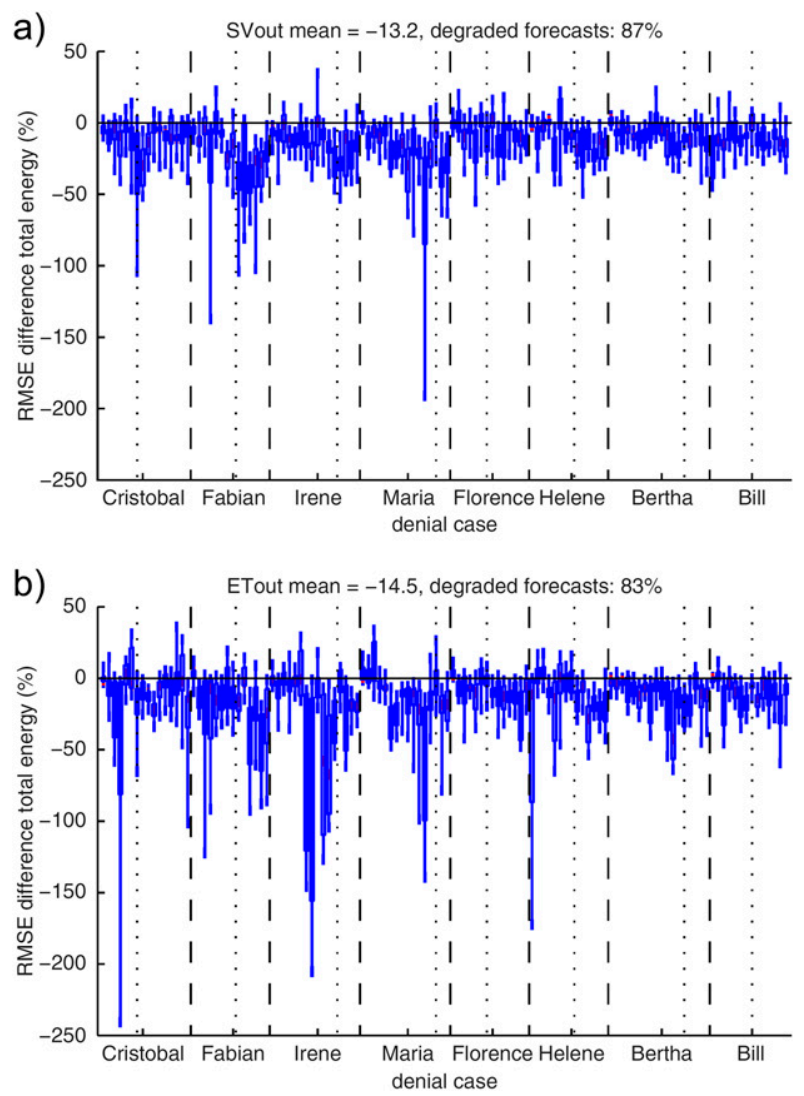

FIG. 17. Forecast degradation due to data denied in (a) extratropical sensitive regions (SVout) and (b) vicinity of the storm (ETout), expressed as root-mean-square difference total energy. Box-and-whisker plot of the percentage impact over Europe $\left(35^{\circ}-\right.$ $75^{\circ} \mathrm{N}, 10^{\circ}-30^{\circ} \mathrm{E}$ ) for all denial cases. The 25 and the 75 quantile, median, and most extreme outliers are indicated by the box edges, red line, and whiskers, respectively. Vertical dashed lines separate ET cases, and vertical dotted lines indicate ET times. [Adapted from Fig. 5 of Anwender et al. (2012).]

baroclinic zone. In addition, the cyclonic circulation of the transitioning cyclone advects anticyclonic PV into the ridge, supporting its further amplification.

This direct impact of ET crucially depends on the phasing between the transitioning cyclone and the developing or already-existing midlatitude wave pattern (section $2 b$ ). The relative position of the transitioning cyclone to a bifurcation point near the tip of the trough in the trough-relative frame of reference determines whether the transitioning cyclone enters a region favorable for cyclone development. The most pronounced impact, in terms of ridge amplification and downstream development, can be expected when the cyclone is located ahead of and moves in phase with an upstream midlatitude trough. In such a phase-locked configuration, the cyclone is able to reintensify and continuously amplify the downstream ridge-trough couplet. In other 
words, the transitioning cyclone acts as a local wave maker, and the ET process can be interpreted as a resonant interaction.

The initial ridge building and the direct impact of ET may further be supported by the so-called preconditioning, introduced in section 2c. Prior to ET, weather systems like warm conveyor belts, predecessor rain events, or diabatic Rossby waves may precondition the midlatitude flow. Through the poleward advection of warm and moist air masses or ridge building ahead of ET, these systems create a midlatitude flow environment that supports a potential reintensification of the transitioning cyclone and the initiation of a highly amplified RWP. The notion of preconditioning is a very recent one, and its general importance for the dynamics and predictability of ET needs further assessment.

To date, understanding of the direct impact of ET on the midlatitude flow is mostly based on modeling studies or compositing approaches using model-based (re) analysis data. Observational data providing information about the dynamics of the interaction and the role of diabatic processes could elucidate how well modelderived results agree with observed ET systems and how operational NWP systems perform in capturing the development. Data from the recent North Atlantic Wave Guide and Downstream Impact Experiment (NAWDEX; Schäfler et al. 2018), which took place in autumn 2016, could provide such valuable observations. NAWDEX featured a unique set of high-resolution measurements for the ET of Hurricane Karl both in clouds and cloud-free regions and that are not assimilated into models on a routine basis. This provides the opportunity for studying diabatic processes during the interaction of a transitioning cyclone with the midlatitude flow and the representation thereof in models at a level of detail previously unavailable. The new generation of high-resolution multispectral imagers, sounders, or scatterometers aboard satellites of the Global Precipitation Measurement (GPM) mission, the Geostationary Operational Environmental Satellite-R (GOES-R) series, or the Himawari-8 are examples of observational resources that may help improve the representation of ET in models on a routine basis.

The direct impact of ET propagates downstream, following RWP dynamics (Fig. 2, blue labels; section 3). Depending on the phasing and the intensity of the interaction between the transitioning cyclone and the midlatitude flow, the cyclone supplies additional eddy kinetic energy to the midlatitude flow, supporting the amplification and downstream propagation of the RWP, as described in section $3 \mathrm{a}(1)$. The development of the RWP, however, also depends on the configuration of the midlatitude flow (section 3a). A weak jet is susceptible to stronger RWP amplification, as compared to a strong jet. Furthermore, the availability of moisture in the downstream region, and the potential formation of downstream cyclones and warm conveyor belts along the eastern flank of the downstream trough, influences the development of the downstream RWP. The diabatically enhanced upper-tropospheric divergent outflow of such weather systems may support the further amplification of the RWP in downstream regions through moist baroclinic growth. Hence, although a weak jet can be expected to yield a high-amplitude wave pattern downstream of ET, the implied weak baroclinicity limits the development of downstream cyclones and, thus, the positive feedback from moist baroclinic growth. This raises the question about the characteristics of an optimal jet that maximizes the downstream response. Besides the amplification of a downstream RWP, ET may also initiate Rossby wave breaking and thus, ultimately, a deamplification of the downstream midlatitude flow.

From a climatological perspective, ET events in the western North Pacific and the south Indian Ocean are accompanied by an enhanced RWP activity in downstream regions [section $3 \mathrm{a}(2)$ ]. The findings for the North Atlantic are less clear, which might be tied to the typically short and weak jet in this region, which is susceptive to Rossby wave breaking. Up to now, the occurrence of Rossby wave breaking during ET has only been considered in a few studies and its occurrence frequency has not been determined yet. Hence, a better understanding of the effect of ET on Rossby wave breaking could help clarify the climatological impact of ET in the North Atlantic.

The amplification of an RWP during ET often results in the development of high-impact weather in downstream regions (section 3b). Heat waves and cold-air outbreaks may develop when the amplified troughs and ridges become stationary. Strong cyclones, deep convection, and heavy precipitation events developing on the eastern flank of the downstream troughs may also be influenced by the downstream impact of ET. Thereby, ET may not primarily be the trigger for the occurrence of such events, but it may at least alter their position and intensity. A climatological assessment and a quantification of the ET's contribution to the formation of such weather events that goes beyond case studies would complement current knowledge and could help to enhance prediction of such events.

The downstream impact of ET often leads to a degradation of predictability in downstream regions (Fig. 2, purple labels; section 4), resulting in increased forecast uncertainty particularly in the medium forecast range. As discussed in section $4 \mathrm{a}$, the primary sources for this 
increase in forecast uncertainty are shortcomings in the representation of diabatic processes in numerical models and a high sensitivity of the subsequent evolution to small changes in phasing. An insufficient representation of latent heat release or the position of the cyclone with respect to the bifurcation point results in rapidly growing forecast errors associated with the amplification of the first downstream ridge. These errors may then propagate downstream with an RWP and may further grow due to nonlinearities in RWP dynamics. Typically, the strongest forecast uncertainty is found for the position and amplitude of the downstream midlatitude Rossby wave pattern, which translates into uncertainty in the geographical location and strength of associated weather systems and their impacts, as discussed in section 4b. Observations may have a beneficial impact on forecast quality during ET, as reviewed in section 4c. In particular, those observations taken near the transitioning cyclone during early stages of ET reduce forecast errors. Observations taken in the surrounding midlatitudes become equally important during later stages of the interaction between the transitioning cyclone and the midlatitude flow.

Given the possible occurrence of high-impact weather downstream of ET, improved predictive capabilities during ET have been, and still are, a major goal of ET research and require further work. A more detailed climatological assessment is needed to better describe forecast degradation experienced during ET, for example, by using reforecast datasets. This assessment should also consider the role of the midlatitude flow configuration in propagating forecast errors into downstream regions and how this differs across the ocean basins. The development of high-resolution, convection-permitting NWP models could help to better capture the diabatic processes during ET. Moreover, this approach, when embedded in global models (e.g., via local grid refinement), may also reduce forecast errors in the medium range. Inherent uncertainty associated with the representation of diabatic processes, however, may limit the predictability of the downstream impact of ET. This motivates the need for improved probabilistic prediction of downstream impacts associated with ET using ensemble prediction systems and additional research on the representation of model errors arising from diabatic processes using techniques such as stochastic physics.

The research summarized in this review primarily focused on assessing the impact of ET on the short-tomedium-range forecast horizon. Preliminary results reveal a statistically significant correlation between monthly mean values of selected teleconnection indices and ET event counts, as well as significant departures from climatology on the subseasonal to seasonal time scale in atmospheric field composites associated with ET events. The potential impact of ET on time scales beyond the medium range calls for a further investigation of the factors that may impact ET on subseasonal to seasonal time scales, including persistent flow regimes and teleconnections, and on how this influences the predictability of ET events on these time scales. Attention should also be paid to ET-related modifications of the midlatitude flow configuration, including enhancements to poleward moisture transport, which may impact both the occurrence frequency and predictability of subseasonal regimes on basin to hemispheric length scales. The Subseasonal to Seasonal Project database (www.s2sprediction.net; Vitart et al. 2017), which provides access to subseasonal to seasonal forecasts from 11 operational centers, could be a valuable resource for such investigations.

On still longer time scales, the influence of a warming climate on the downstream impact of ET, in particular, is another aspect that deserves attention. Considering the important contribution of diabatic processes to the amplification of the downstream midlatitude RWP during ET, the increasing availability of water vapor in a changing climate suggests that an associated increase in latent heat release may strengthen impacts such as downstream ridge amplification. Research is needed to address this question and to explore how this extreme form of tropical-extratropical interaction could change with a changing climate.

Acknowledgments. The paper was jointly written by Julia H. Keller, Christian M. Grams, and Michael Riemer, based on contributions from all coauthors. We thank John Gyakum for his support in initiating this work, as well as Clark Evans for comments that helped to improve the manuscript. Well-thought-out and thorough comments by five anonymous reviewers and the editor David Schultz on a previous version of the manuscript provided very helpful guidance for improving the content and tangibility of this review. CMG, JHK, and MR would like to thank Sarah Jones for sparking their interest in ET and for making parts of the work presented here happen. The contribution by CMG was made while he held a Swiss National Science Foundation (SNSF) Ambizione fellowship under Grant PZ00P2_148177/1 and finished under Grant VH-NG-1243 of the Helmholtz Association. MR acknowledges support from the subproject "A4: Evolution and predictability of storm structure during extratropical transition of tropical cyclones" of the Transregional Collaborative Research Center SFB/TRR 165 "Waves to Weather" program funded by the German Science Foundation (DFG). Parts of the results presented in this review 
have been produced within the German PANDOWAE (FOR896) project, funded by DFG as a contribution to the WMO World Weather Research Programme THORPEX. Coauthors acknowledge the following support: Bosart from NSF (AGS-1240502 and AGS1355960); Doyle and Reynolds from the Chief of Naval Research through the NRL Base Program PE 0601153N and the ONR PE 0602435N; Quinting from the Australian Research Council Centre of Excellence for Climate System Science (CE110001028); Torn from NSF (ATM-1461753); and Zhang from ONR (Grant N000140910526). This review was partly initiated at the World Meteorological Organization's Eighth International Workshop on Tropical Cyclones in 2014.

\section{REFERENCES}

Agustí-Panareda, A., C. D. Thorncroft, G. C. Craig, and S. L. Gray, 2004: The extratropical transition of Hurricane Irene (1999): A potential-vorticity perspective. Quart. J. Roy. Meteor. Soc., 130, 1047-1074, https://doi.org/10.1256/qj.02.140.

— S. L. Gray, G. C. Craig, and C. Thorncroft, 2005: The extratropical transition of Tropical Cyclone Lili (1996) and its crucial contribution to a moderate extratropical development. Mon. Wea. Rev., 133, 1562-1573, https://doi.org/10.1175/MWR2935.1.

Aiyyer, A., 2015: Recurving western North Pacific tropical cyclones and midlatitude predictability. Geophys. Res. Lett., 42, 7799-7807, https://doi.org/10.1002/2015GL065082.

AIR Worldwide, 2015: Japan flood Typhoon Etau. AIR Worldwide, accessed 21 June 2018, https://alert.air-worldwide.com/ EventSummary.aspx $? \mathrm{e}=808 \& \mathrm{tp}=62 \& \mathrm{c}=1$.

Anwender, D., P. A. Harr, and S. C. Jones, 2008: Predictability associated with the downstream impacts of the extratropical transition of tropical cyclones: Case studies. Mon. Wea. Rev., 136, 3226-3247, https://doi.org/10.1175/2008MWR2249.1.

— S. C. Jones, M. Leutbecher, and P. A. Harr, 2010: Sensitivity experiments for ensemble forecasts of the extratropical transition of Typhoon Tokage (2004). Quart. J. Roy. Meteor. Soc., 136, 183-200, https://doi.org/10.1002/qj.527.

— C. Cardinali, and S. C. Jones, 2012: Data denial experiments for extratropical transition. Tellus, 64A, 19151, https://doi.org/ 10.3402/tellusa.v64i0.19151.

Archambault, H. M., L. F. Bosart, D. Keyser, and J. M. Cordeira, 2013: A climatological analysis of the extratropical flow response to recurving western North Pacific tropical cyclones. Mon. Wea. Rev., 141, 2325-2346, https://doi.org/10.1175/ MWR-D-12-00257.1.

— D. Keyser, L. F. Bosart, C. A. Davis, and J. M. Cordeira, 2015: A composite perspective of the extratropical flow response to recurving western North Pacific tropical cyclones. Mon. Wea. Rev., 143, 1122-1141, https://doi.org/10.1175/MWR-D-14-00270.1.

Atallah, E. H., and L. F. Bosart, 2003: The extratropical transition and precipitation distribution of Hurricane Floyd (1999). Mon. Wea. Rev., 131, 1063-1081, https://doi.org/10.1175/15200493(2003)131<1063:TETAPD>2.0.CO;2.

Baek, E.-H., J.-H. Kim, J.-S. Kug, and G.-H. Lim, 2013: Favorable versus unfavorable synoptic backgrounds for indirect precipitation events ahead of tropical cyclones approaching the Korean peninsula: A comparison of two cases. Asia-Pac. J. Atmos. Sci., 49, 333-346, https://doi.org/10.1007/s13143-013-0032-z.
Bao, X., and Coauthors, 2015: Diagnostics for an extreme rain event near Shanghai during the landfall of Typhoon Fitow (2013). Mon. Wea. Rev., 143, 3377-3405, https://doi.org/10.1175/ MWR-D-14-00241.1.

Baumgart, M., M. Riemer, V. Wirth, F. Teubler, and S. T. K. Lang, 2018: Potential vorticity dynamics of forecast errors: A quantitative case study. Mon. Wea. Rev., 146, 1405-1425, https://doi.org/10.1175/MWR-D-17-0196.1.

Blake, E. S., T. B. Kimberlain, R. J. Berg, J. P. Cangialosi, and J. L. Beven, 2013: Hurricane Sandy. National Hurricane Center Tropical Cyclone Rep. AL182012, 157 pp., https://www.nhc.noaa.gov/ data/tcr/AL182012_Sandy.pdf.

Bosart, L. F., 2003: Tropopause folding, upper-level frontogenesis, and beyond. A Half Century of Progress in Meteorology: A Tribute to Richard Reed, Meteor. Monogr., No. 31, Amer. Meteor. Soc., 13-47, https://doi.org/10.1007/978-1-878220-69-1_2. , and F. H. Carr, 1978: A case study of excessive rainfall centered around Wellsville, New York, 20-21 June 1972. Mon. Wea. Rev. 106, 348-362, https://doi.org/10.1175/1520-0493(1978)106<0348: ACSOER $>2.0 . C O ; 2$.

— , J. M. Cordeira, T. J. Galarneau, B. J. Moore, and H. M. Archambault, 2012: An analysis of multiple predecessor rain events ahead of Tropical Cyclones Ike and Lowell: 10 15 September 2008. Mon. Wea. Rev., 140, 1081-1107, https:// doi.org/10.1175/MWR-D-11-00163.1.

_ P. P. Papin, A. M. Bentley, B. J. Moore, and A. C. Winters, 2015: Large-scale antecedent conditions associated with 2014 2015 winter onset over North America and mid-winter storminess along the North Atlantic coast. 17th Cyclone Workshop, Pacific Grove, CA, Cyclone Workshop Organizing Committee, 1 pp.

Brown, D. P., 2015: Hurricane Gonzalo. National Hurricane Center Tropical Cyclone Rep. AL082014,30 pp., https://www.nhc.noaa.gov/ data/tcr/AL082014_Gonzalo.pdf.

Buizza, R., J. Tribbia, F. Molteni, and T. Palmer, 1993: Computation of optimal unstable structures for a numerical weather prediction model. Tellus, 45A, 388-407, https://doi.org/ 10.3402/tellusa.v45i5.14901.

Byun, K.-Y., and T.-Y. Lee, 2012: Remote effects of tropical cyclones on heavy rainfall over the Korean peninsula-Statistical and composite analysis. Tellus, 64A, 14983, https://doi.org/10.3402/ tellusa.v64i0.14983.

Cardinali, C., R. Buizza, G. Kelly, M. Shapiro, and J.-N. Thépaut, 2007: The value of observations. III: Influence of weather regimes on targeting. Quart. J. Roy. Meteor. Soc., 133, 18331842, https://doi.org/10.1002/qj.148.

Chaboureau, J.-P., F. Pantillon, D. Lambert, E. Richard, and C. Claud, 2012: Tropical transition of a Mediterranean storm by jet crossing. Quart. J. Roy. Meteor. Soc., 138, 596-611, https://doi.org/10.1002/qj.960.

Chen, H., and W. Pan, 2010: Targeting studies for the extratropical transition of Hurricane Fabian: Signal propagation, the interaction between Fabian and midlatitude flow, and an observation strategy. Mon. Wea. Rev., 138, 3224-3242, https:// doi.org/10.1175/2010MWR2888.1.

Cordeira, J. M., F. M. Ralph, and B. J. Moore, 2013: The development and evolution of two atmospheric rivers in proximity to western North Pacific tropical cyclones in October 2010. Mon. Wea. Rev., 141, 4234-4255, https://doi.org/10.1175/MWR-D-13-00019.1.

Cote, M. R., 2007: Predecessor rain events in advance of tropical cyclones. M.S. thesis, Department of Earth and Atmospheric Sciences, University at Albany, State University of New York, 200 pp. 
Cunningham, P., and D. Keyser, 2000: Analytical and numerical modelling of jet streaks: Barotropic dynamics. Quart. J. Roy. Meteor. Soc., 126, 3187-3217, https://doi.org/10.1002/ qj.49712657010.

Davies, H. C., and M. Didone, 2013: Diagnosis and dynamics of forecast error growth. Mon. Wea. Rev., 141, 2483-2501, https:// doi.org/10.1175/MWR-D-12-00242.1.

_ - C. Schär, and H. Wernli, 1991: The palette of fronts and cyclones within a baroclinic wave development. J. Atmos. Sci., 48, 1666-1689, https://doi.org/10.1175/1520-0469(1991)048<1666: TPOFAC $>2.0 . \mathrm{CO} ; 2$.

Davis, C. A., and K. A. Emanuel, 1991: Potential vorticity diagnostics of cyclogenesis. Mon. Wea. Rev., 119, 1929-1953, https://doi.org/ 10.1175/1520-0493(1991)119<1929:PVDOC > 2.0.CO;2.

—, M. Stoelinga, and Y. H. Kuo, 1993: The integrated effect of condensation in numerical simulations of extratropical cyclogenesis. Mon. Wea. Rev., 121, 2309-2330, https://doi.org/ 10.1175/1520-0493(1993)121<2309:TIEOCI >2.0.CO;2.

Dirren, S., M. Didone, and H. C. Davies, 2003: Diagnosis of "forecastanalysis" differences of a weather prediction system. Geophys. Res. Lett., 30, 2060, https://doi.org/10.1029/2003GL017986.

Doyle, J. D., C. A. Reynolds, and C. Amerault, 2011: Diagnosing tropical cyclone sensitivity. Comput. Sci. Eng., 13, 31-39, https://doi.org/10.1109/MCSE.2010.146.

$-, \ldots,-\ldots$, and J. Moskaitis, 2012: Adjoint sensitivity and predictability of tropical cyclogenesis. J. Atmos. Sci., 69, 35353557, https://doi.org/10.1175/JAS-D-12-0110.1.

Evans, C., and R. E. Hart, 2008: Analysis of the wind field evolution associated with the extratropical transition of Bonnie (1998). Mon. Wea. Rev., 136, 2047-2065, https://doi.org/10.1175/ 2007MWR2051.1.

- , and Coauthors, 2017: The extratropical transition of tropical cyclones. Part I: Cyclone evolution and direct impacts. Mon. Wea. Rev., 145, 4317-4344, https://doi.org/10.1175/MWR-D-17-0027.1.

Feser, F., M. Schubert-Frisius, H. von Storch, M. Zahn, M. Barcikowska, S. Haeseler, C. Lefebvre, and M. Stendel, 2015: Hurricane Gonzalo and its extratropical transition to a strong European storm. Bull. Amer. Meteor. Soc., 96, S51-S55, https://doi.org/10.1175/BAMS-D-15-00122.1.

Galarneau, T. J., 2015: Influence of a predecessor rain event on the track of Tropical Cyclone Isaac (2012). Mon. Wea. Rev., 143, 3354-3376, https://doi.org/10.1175/MWR-D-15-0053.1.

— L. L. F. Bosart, and R. S. Schumacher, 2010: Predecessor rain events ahead of tropical cyclones. Mon. Wea. Rev., 138, 32723297, https://doi.org/10.1175/2010MWR3243.1.

—, R. McTaggart-Cowan, L. F. Bosart, and C. A. Davis, 2015: Development of North Atlantic tropical disturbances near upper-level potential vorticity streamers. J. Atmos. Sci., 72 572-597, https://doi.org/10.1175/JAS-D-14-0106.1.

Grams, C. M., 2011: Quantification of the downstream impact of extratropical transition for Typhoon Jangmi and other case studies. Ph.D. dissertation, Karlsruhe Institute of Technology, 334 pp., https://doi.org/10.5445/KSP/1000024940.

_ 2013: Quantification of Hurricane Sandy's impact on the midlatitude flow. 16th Cyclone Workshop, Sainte-Adèle, Quebéc, Canada, Cyclone Workshop Organizing Committee, 1 pp.

__ , and S. R. Blumer, 2015: European high-impact weather caused by the downstream response to the extratropica transition of North Atlantic Hurricane Katia (2011). Geophys. Res. Lett., 42, 8738-8748, https://doi.org/10.1002/ 2015GL066253.

— , and H. M. Archambault, 2016: The key role of diabatic outflow in amplifying the midlatitude flow: A representative case study of weather systems surrounding western North Pacific extratropical transition. Mon. Wea. Rev., 144, 38473869, https://doi.org/10.1175/MWR-D-15-0419.1.

, and Coauthors, 2011: The key role of diabatic processes in modifying the upper-tropospheric wave guide: A North Atlantic case-study. Quart. J. Roy. Meteor. Soc., 137, 2174-2193, https:// doi.org/10.1002/qj.891.

S. C. Jones, C. A. Davis, P. A. Harr, and M. Weissmann, 2013a: The impact of Typhoon Jangmi (2008) on the midlatitude flow. Part I: Upper-level ridgebuilding and modification of the jet. Quart. J. Roy. Meteor. Soc., 139, 2148-2164, https://doi.org/10.1002/qj.2091.

- — - and - 2013b: The impact of Typhoon Jangmi (2008) on the midlatitude flow. Part II: Downstream evolution. Quart. J. Roy. Meteor. Soc., 139, 2165-2180, https://doi.org/ 10.1002/qj.2119.

— S. T. K. Lang, and J. H. Keller, 2015: A quantitative assessment of the sensitivity of the downstream midlatitude flow response to extratropical transition of tropical cyclones. Geophys. Res. Lett., 42, 9521-9529, https://doi.org/10.1002/ 2015GL065764.

— , L. Magnusson, and E. Madonna, 2018: An atmospheric dynamics perspective on the amplification and propagation of forecast error in numerical weather prediction models: A case study. Quart. J. Roy. Meteor. Soc., 144, 2577-2591, https://doi.org/ 10.1002/qj.3353.

Griffin, K. S., and L. F. Bosart, 2014: The extratropical transition of Tropical Cyclone Edisoana (1990). Mon. Wea. Rev., 142, 2772-2793, https://doi.org/10.1175/MWR-D-13-00282.1.

Gutowski, W. J., L. E. Branscome, and D. A. Stewart, 1992: Life cycles of moist baroclinic eddies. J. Atmos. Sci., 49, 306-319, https:// doi.org/10.1175/1520-0469(1992)049<0306:LCOMBE >2.0.CO;2.

Hakim, G. J., 2000: Role of nonmodal growth and nonlinearity in cyclogenesis initial-value problems. J. Atmos. Sci., 57, 2951-2967, https://doi.org/10.1175/1520-0469(2000)057<2951: RONGAN $>2.0 . \mathrm{CO} ; 2$.

Halverson, J. B., and T. Rabenhorst, 2013: Hurricane Sandy: The science and impacts of a superstorm. Weatherwise, 66, 14-23, https://doi.org/10.1080/00431672.2013.762838.

Hardy, S., D. M. Schultz, and G. Vaughan, 2017a: Early evolution of the 23-26 September 2012 U.K. Floods: Tropical Storm Nadine and diabatic heating due to cloud microphysics. Mon. Wea. Rev., 145, 543-563, https://doi.org/10.1175/MWR-D-160200.1 .

_ — , and _ 2017b: The 23-26 September 2012 U.K. Floods: Using PV surgery to quantify sensitivity to upper-level forcing. Mon. Wea. Rev., 145, 4055-4079, https://doi.org/ 10.1175/MWR-D-16-0434.1.

Harr, P. A., and J. M. Dea, 2009: Downstream development associated with the extratropical transition of tropical cyclones over the western North Pacific. Mon. Wea. Rev., 137, 12951319, https://doi.org/10.1175/2008MWR2558.1.

_ , and H. M. Archambault, 2016: Dynamics, predictability, and high-impact weather associated with the extratropical transition of tropical cyclones. Dynamics and Predictability of Large-Scale, High-Impact Weather and Climate Events, J. Li et al., Eds., Cambridge University Press, 153-167, https:// doi.org/10.1017/CBO9781107775541.013.

_, R. L. Elsberry, and T. F. Hogan, 2000: Extratropical transition of tropical cyclones over the western North Pacific. Part II: The impact of midlatitude circulation characteristics. Mon. Wea. Rev., 128, 2634-2653, https://doi.org/10.1175/ 1520-0493(2000)128<2634:ETOTCO>2.0.CO;2. 
— D. Anwender, and S. C. Jones, 2008: Predictability associated with the downstream impacts of the extratropical transition of tropical cyclones: Methodology and a case study of Typhoon Nabi (2005). Mon. Wea. Rev., 136, 3205-3225, https://doi.org/ 10.1175/2008MWR2248.1.

Hodyss, D., and E. Hendricks, 2010: The resonant excitation of baroclinic waves by the divergent circulation of recurving tropical cyclones. J. Atmos. Sci., 67, 3600-3616, https://doi.org/ 10.1175/2010JAS3459.1.

Hoskins, B. and P. Berrisford, 1988: A potential vorticity perspective of the storm of 15-16 October 1987. Weather, 43, 122129, https://doi.org/10.1002/j.1477-8696.1988.tb03890.x.

Jones, S. C., and Coauthors, 2003: The extratropical transition of tropical cyclones: Forecast challenges, current understanding, and future directions. Wea. Forecasting, 18, 1052-1092, https://doi.org/ 10.1175/1520-0434(2003)018<1052:TETOTC >2.0.CO;2.

Joos, H., and H. Wernli, 2012: Influence of microphysical processes on the potential vorticity development in a warm conveyor belt: A case-study with the limited-area model COSMO. Quart. J. Roy. Meteor. Soc., 138, 407-418, https://doi.org/10.1002/qj.934. , and R. M. Forbes, 2016: Impact of different IFS microphysics on a warm conveyor belt and the downstream flow evolution. Quart. J. Roy. Meteor. Soc., 142, 2727-2739, https://doi.org/ 10.1002/qj.2863.

Keller, J. H., 2017: Amplification of the downstream wave train during extratropical transition: Sensitivity studies. Mon. Wea. Rev., 145, 1529-1548, https://doi.org/10.1175/ MWR-D-16-0193.1.

— , and C. M. Grams, 2015: The extratropical transition of Typhoon Choi-Wan (2009) and its role in the formation of North American high-impact weather. 17th Cyclone Workshop, Pacific Grove, CA, Cyclone Workshop Organizing Committee, 1 pp., http://www.atmos.albany.edu/facstaff/kristen/CW17/ Poster/Keller.pdf.

— S. C. Jones, J. L. Evans, and P. A. Harr, 2011: Characteristics of the TIGGE multimodel ensemble prediction system in representing forecast variability associated with extratropical transition. Geophys. Res. Lett., 38, L12802, https://doi.org/ 10.1029/2011GL047275.

,,-- and P. A. Harr, 2014: An eddy kinetic energy view of physical and dynamical processes in distinct forecast scenarios for the extratropical transition of two tropical cyclones. Mon. Wea. Rev., 142, 2751-2771, https://doi.org/10.1175/MWR-D13-00219.1.

Kim, H. M., and B.-J. Jung, 2009: Singular vector structure and evolution of a recurving tropical cyclone. Mon. Wea. Rev., 137, 505-524, https://doi.org/10.1175/2008MWR2643.1.

Kitabatake, N., 2002: The role of convective instability and frontogenetic circulation in the torrential rainfall in the Tokai district on 11-12 September 2000 (in Japanese). Pap. Meteor. Geophys., 53, 91-108, https://doi.org/10.2467/mripapers.53.91.

,- H. Tsuguti, and T. Kato, 2017: Effects of synoptic-scale environmental flows on the heavy rainfall event in the Kanto and Tohoku district in September 2015 (in Japanese). Tenki, 64, 887899, https://www.metsoc.jp/tenki/pdf/2017/2017_12_0041.pdf.

Klein, P. M., P. A. Harr, and R. L. Elsberry, 2002: Extratropical transition of western North Pacific tropical cyclones: Midlatitude and tropical cyclone contributions to reintensification. Mon. Wea. Rev., 130, 2240-2259, https://doi.org/10.1175/15200493(2002)130<2240:ETOWNP > 2.0.CO;2.

Knapp, K. R., and Coauthors, 2011: Globally gridded satellite observations for climate studies. Bull. Amer. Meteor. Soc., 92, 893-907, https://doi.org/10.1175/2011BAMS3039.1.
Komaromi, W. A., and J. D. Doyle, 2018: On the dynamics of tropical cyclone and trough interactions. J. Atmos. Sci., 75, 2687-2709, https://doi.org/10.1175/JAS-D-17-0272.1.

Kowaleski, A. M., and J. L. Evans, 2016: Regression mixture model clustering of multimodel ensemble forecasts of Hurricane Sandy: Partition characteristics. Mon. Wea. Rev., 144, 38253846, https://doi.org/10.1175/MWR-D-16-0099.1.

Kumpf, A., M. Rautenhaus, M. Riemer, and R. Westermann, 2019: Visual analysis of the temporal evolution of ensemble forecast sensitivities. IEEE Trans. Visualization Comput. Graphics, $\mathbf{2 5}$, 98-108, https://doi.org/10.1109/TVCG.2018.2864901.

Lamberson, W. S., R. D. Torn, L. F. Bosart, and L. Magnusson, 2016: Diagnosis of the source and evolution of medium-range forecast errors for Extratropical Cyclone Joachim. Wea. Forecasting, 31, 1197-1214, https://doi.org/10.1175/WAF-D-16-0026.1.

Lang, A. A., and J. E. Martin, 2013: The structure and evolution of lower stratospheric frontal zones. Part II: The influence of tropospheric ascent on lower stratospheric frontal development. Quart. J. Roy. Meteor. Soc., 139, 1798-1809, https://doi.org/10.1002/qj.2074.

Lang, S. T. K., M. Leutbecher, and S. C. Jones, 2012a: Impact of perturbation methods in the ECMWF ensemble prediction system on tropical cyclone forecasts. Quart. J. Roy. Meteor. Soc., 138, 2030-2046, https://doi.org/10.1002/qj.1942.

Lang, A. A., S. C. Jones, M. Leutbecher, M. S. Peng, and C. A. Reynolds, 2012b: Sensitivity, structure, and dynamics of singular vectors associated with Hurricane Helene (2006). J. Atmos. Sci., 69, 675-694, https://doi.org/10.1175/JAS-D-11-048.1.

Lazear, R. A., and M. C. Morgan, 2006: The influence of tropical cyclone outflow on the Northern Hemisphere subtropical and tropical general circulation. 27th Conf. on Hurricanes and Tropical Meteorology, Monterey, CA, Amer. Meteor. Soc., 11C.4, https:// ams.confex.com/ams/27Hurricanes/webprogram/Paper108762.html.

Majumdar, S. J., 2016: A review of targeted observations. Bull. Amer. Meteor. Soc., 97, 2287-2303, https://doi.org/10.1175/ BAMS-D-14-00259.1.

Martius, O., C. Schwierz, and H. C. Davies, 2008: Far-upstream precursors of heavy precipitation events on the Alpine southside. Quart. J. Roy. Meteor. Soc., 134, 417-428, https://doi.org/ 10.1002/qj.229.

— , and Coauthors, 2013: The role of upper-level dynamics and surface processes for the Pakistan flood of July 2010. Quart. J. Roy. Meteor. Soc., 139, 1780-1797, https://doi.org/10.1002/qj.2082.

McTaggart-Cowan, R., J. R. Gyakum, and M. K. Yau, 2001: Sensitivity testing of extratropical transitions using potential vorticity inversions to modify initial conditions: Hurricane Earl case study. Mon. Wea. Rev., 129, 1617-1636, https://doi.org/ 10.1175/1520-0493(2001)129<1617:STOETU>2.0.CO;2.

,-- , and,- 2003 : The influence of the downstream state on extratropical transition: Hurricane Earl (1998) case study. Mon. Wea. Rev., 131, 1910-1929, https://doi.org/10.1175//2589.1.

,-- , and,- 2004 : The impact of tropical remnants on extratropical cyclogenesis: Case study of Hurricanes Danielle and Earl (1998). Mon. Wea. Rev., 132, 1933-1951, https://doi.org/ 10.1175/1520-0493(2004)132<1933:TIOTRO>2.0.CO;2.

_ , E. H. Atallah, J. R. Gyakum, and L. F. Bosart, 2006a: Hurricane Juan (2003). Part I: A diagnostic and compositing life cycle study. Mon. Wea. Rev., 134, 1725-1747, https://doi.org/ 10.1175/MWR3142.1.

_ L. F. Bosart, J. R. Gyakum, and E. H. Atallah, 2006b: Hurricane Juan (2003). Part II: Forecasting and numerical simulation. Mon. Wea. Rev., 134, 1748-1771, https://doi.org/10.1175/MWR3143.1. , and — 2007: Hurricane Katrina (2005). Part II: Evolution and hemispheric impacts of a diabatically generated 
warm pool. Mon. Wea. Rev., 135, 3927-3949, https://doi.org/ 10.1175/2007MWR2096.1.

—, J. R. Gyakum, and R. W. Moore, 2017: The baroclinic moisture flux. Mon. Wea. Rev., 145, 25-47, https://doi.org/10.1175/ MWR-D-16-0153.1.

Moore, B. J., L. F. Bosart, D. Keyser, and M. L. Jurewicz, 2013: Synoptic-scale environments of predecessor rain events occurring east of the Rocky Mountains in association with Atlantic basin tropical cyclones. Mon. Wea. Rev., 141, 1022-1047, https://doi.org/ 10.1175/MWR-D-12-00178.1.

Moore, R. W., O. Martius, and H. C. Davies, 2008: Downstream development and Kona low genesis. Geophys. Res. Lett., 35, L20814, https://doi.org/10.1029/2008GL035502.

Munsell, E. B., and F. Zhang, 2014: Prediction and uncertainty of Hurricane Sandy (2012) explored through a real-time cloudpermitting ensemble analysis and forecast system assimilating airborne Doppler radar observations. J. Adv. Model. Earth Syst., 6, 38-58, https://doi.org/10.1002/2013MS000297.

_, J. A. Sippel, S. A. Braun, Y. Weng, and F. Zhang, 2015: Dynamics and predictability of Hurricane Nadine (2012) evaluated through convection-permitting ensemble analysis and forecasts. Mon. Wea. Rev., 143, 4514-4532, https://doi.org/ 10.1175/MWR-D-14-00358.1.

Nakamura, H., M. Nakamura, and J. L. Anderson, 1997: The role of high- and low-frequency dynamics in blocking formation. Mon. Wea. Rev., 125, 2074-2093, https://doi.org/10.1175/15200493(1997)125<2074:TROHAL > 2.0.CO;2.

Neiman, P. J., M. A. Shapiro, and L. S. Fedor, 1993: The life cycle of an extratropical marine cyclone. Part II: Mesoscale structure and diagnostics. Mon. Wea. Rev., 121, 2177-2199, https://doi.org/ 10.1175/1520-0493(1993)121<2177:TLCOAE > 2.0.CO;2.

NHC, 2017: Forecast verification. National Hurricane Center, accessed 3 June 2018, https://www.nhc.noaa.gov/verification/.

Orlanski, I., and J. P. Sheldon, 1995: Stages in the energetics of baroclinic systems. Tellus, 47A, 605-628, https://doi.org/10.3402/ tellusa.v47i5.11553.

Palmén, E., 1958: Vertical circulation and release of kinetic energy during the development of Hurricane Hazel into an extratropical storm. Tellus, 10,1-13, https://doi.org/10.3402/ tellusa.v10i1.9222.

Pantillon, F., J.-P. Chaboureau, C. Lac, and P. Mascart, 2013a: On the role of a Rossby wave train during the extratropical transition of Hurricane Helene (2006). Quart. J. Roy. Meteor. Soc., 139, 370-386, https://doi.org/10.1002/qj.1974.

,-- , P. J. Mascart, and C. Lac, 2013b: Predictability of a Mediterranean tropical-like storm downstream of the extratropical transition of Hurricane Helene (2006). Mon. Wea. Rev., 141, 1943-1962, https://doi.org/10.1175/MWR-D-12-00164.1.

,-- , and E. Richard, 2015: Remote impact of North Atlantic hurricanes on the Mediterranean during episodes of intense rainfall in autumn 2012. Quart. J. Roy. Meteor. Soc., 141, 967 978, https://doi.org/10.1002/qj.2419.

,-- , and,- 2016 : Vortex-vortex interaction between Hurricane Nadine (2012) and an Atlantic cut-off dropping the predictability over the Mediterranean. Quart. J. Roy. Meteor. Soc., 142, 419-432, https://doi.org/10.1002/qj.2635.

Parker, T. J., G. J. Berry, and M. J. Reeder, 2013: The influence of tropical cyclones on heat waves in southeastern Australia Geophys. Res. Lett., 40, 6264-6270, https://doi.org/10.1002/ 2013 GL058257.

,-- , and — 2014: The structure and evolution of heat waves in southeastern Australia. J. Climate, 27, 5768-5785, https://doi.org/10.1175/JCLI-D-13-00740.1.
Parsons, D. B., and Coauthors, 2017: THORPEX research and the science of prediction. Bull. Amer. Meteor. Soc., 98, 807-830, https://doi.org/10.1175/BAMS-D-14-00025.1.

Petterssen, S., and S. J. Smebye, 1971: On the development of extratropical cyclones. Quart. J. Roy. Meteor. Soc., 97, 457-482, https://doi.org/10.1002/qj.49709741407.

Pinto, J. M., M. Klawa, U. Ulbrich, S. Ruradi, and P. Speth, 2001: Extreme precipitation events over northwest Italy and their relationship with tropical-extratropical interactions over the Atlantic: Mediterranean storms. Proc. Third EGU Plinius Conf., Baja Sardinia, Italy, EGU, 327-332.

Pryles, K. D., and E. A. Ritchie, 2016: Investigation of tropical cyclone extratropical transition and downstream flow effects. 32nd Conf. on Hurricanes and Tropical Meteorology, San Juan, Puerto Rico, Amer. Meteor. Soc., https://ams.confex. com/ams/32Hurr/webprogram/Paper293835.html.

Quinting, J. F., and S. C. Jones, 2016: On the impact of tropical cyclones on Rossby wave packets: A climatological perspective. Mon. Wea. Rev., 144, 2021-2048, https://doi.org/10.1175/ MWR-D-14-00298.1.

and M. J. Reeder, 2017: Southeastern Australian heat waves from a trajectory viewpoint. Mon. Wea. Rev., 145, 4109-4125, https://doi.org/10.1175/MWR-D-17-0165.1.

Renwick, J. A., and M. J. Revell, 1999: Blocking over the South Pacific and Rossby wave propagation. Mon. Wea. Rev., 127, 2233-2247, https://doi.org/10.1175/1520-0493(1999)127<2233: BOTSPA $>2.0 . \mathrm{CO} ; 2$.

Reynolds, C. A., M. S. Peng, and J.-H. Chen, 2009: Recurving tropical cyclones: Singular vector sensitivity and downstream impacts. Mon. Wea. Rev., 137, 1320-1337, https://doi.org/ 10.1175/2008MWR2652.1.

Riboldi, J., M. Röthlisberger, and C. M. Grams, 2018: Rossby wave initiation by recurving tropical cyclones in the western North Pacific. Mon. Wea. Rev., 146, 1283-1301, https://doi.org/ 10.1175/MWR-D-17-0219.1.

_ C. M. Grams, M. Riemer, and H. M. Archambault, 2019: A phase locking perspective on Rossby wave amplification and atmospheric blocking downstream of recurving western North Pacific tropical cyclones. Mon. Wea. Rev., 147, 567-589, https:// doi.org/10.1175/MWR-D-18-0271.1.

Riemer, M., and S. C. Jones, 2010: The downstream impact of tropical cyclones on a developing baroclinic wave in idealized scenarios of extratropical transition. Quart. J. Roy. Meteor. Soc., 136, 617-637, https://doi.org/10.1002/qj.605.

, and - 2014: Interaction of a tropical cyclone with a highamplitude, midlatitude wave pattern: Waviness analysis, trough deformation and track bifurcation. Quart. J. Roy. Meteor. Soc., 140, 1362-1376, https://doi.org/10.1002/qj.2221.

— - , and C. A. Davis, 2008: The impact of extratropical transition on the downstream flow: An idealized modelling study with a straight jet. Quart. J. Roy. Meteor. Soc., 134, 6991, https://doi.org/10.1002/qj.189.

, M. Baumgart, and S. Eiermann, 2014: Cyclogenesis downstream of extratropical transition analyzed by Q-vector partitioning based on flow geometry. J. Atmos. Sci., 71, 42044220, https://doi.org/10.1175/JAS-D-14-0023.1.

Ritchie, E. A., and R. L. Elsberry, 2003: Simulations of the extratropical transition of tropical cyclones: Contributions by the midlatitude upper-level trough to reintensification. Mon. Wea. Rev., 131, 2112-2128, https://doi.org/10.1175/1520-0493(2003) $131<2112:$ SOTETO $>2.0 . \mathrm{CO} ; 2$

, and - 2007: Simulations of the extratropical transition of tropical cyclones: Phasing between the upper-level trough and 
tropical cyclones. Mon. Wea. Rev., 135, 862-876, https://doi.org/ 10.1175/MWR3303.1.

Röbcke, M., S. C. Jones, and D. Majewski, 2004: The extratropical transition of Hurricane Erin (2001): A potential vorticity perspective. Meteor. Z., 13, 511-525, https://doi.org/10.1127/ 0941-2948/2004/0013-0511.

Rodwell, M. J., Rodwell, M. J., and Coauthors, 2013: Characteristics of occasional poor medium-range weather forecasts for Europe. Bull. Amer. Meteor. Soc., 94, 1393-1405, https://doi.org/10.1175/ BAMS-D-12-00099.1.

Röthlisberger, M., O. Martius, and H. Wernli, 2016: An algorithm for identifying the initiation of synoptic-scale Rossby waves on potential vorticity waveguides. Quart. J. Roy. Meteor. Soc., 142, 889-900, https://doi.org/10.1002/qj.2690.

$\longrightarrow,-$, and $\longrightarrow, 2018$ : Northern Hemisphere Rossby wave initiation events on the extratropical jet-A climatological analysis. J. Climate, 31, 743-760, https://doi.org/10.1175/JCLI-D-17-0346.1.

Sardeshmukh, P. D., and B. J. Hoskins, 1988: The generation of global rotational flow by steady idealized tropical divergence. J. Atmos. Sci., 45, 1228-1251, https://doi.org/10.1175/15200469(1988)045<1228:TGOGRF>2.0.CO;2.

Schäfler, A., and Coauthors, 2018: The North Atlantic Waveguide and Downstream Impact Experiment. Bull. Amer. Meteor. Soc., 99, 1607-1637, https://doi.org/10.1175/BAMS-D-17-0003.1.

Scheck, L., S. C. Jones, and M. Juckes, 2011a: The resonant interaction of a tropical cyclone and a tropopause front in a barotropic model. Part I: Zonally oriented front. J. Atmos. Sci., 68, 405-419, https://doi.org/10.1175/2010JAS3482.1.

,,-- and $-2011 \mathrm{~b}$ : The resonant interaction of a tropical cyclone and a tropopause front in a barotropic model. Part II: Frontal waves. J. Atmos. Sci., 68, 420-429, https://doi.org/ 10.1175/2010JAS3483.1.

Schumacher, R. S., and T. J. Galarneau, 2012: Moisture transport into midlatitudes ahead of recurving tropical cyclones and its relevance in two predecessor rain events. Mon. Wea. Rev., 140, 1810-1827, https://doi.org/10.1175/MWR-D-11-00307.1.

$\longrightarrow, \ldots$, and L. F. Bosart, 2011: Distant effects of a recurving tropical cyclone on rainfall in a midlatitude convective system: A high-impact predecessor rain event. Mon. Wea. Rev., 139, 650-667, https://doi.org/10.1175/2010MWR3453.1.

Sekioka, M., 1956: A hypothesis on complex of tropical and extratropical cyclones for typhoon in the middle latitudes. J. Meteor. Soc. Japan Ser. II, 35, 170-173, https://doi.org/ 10.2151/jmsj1923.35.3_170.

Simmons, A. J., and B. J. Hoskins, 1979: The downstream and upstream development of unstable baroclinic waves. J. Atmos. Sci., 36, 1239-1254, https://doi.org/10.1175/1520-0469(1979) 036<1239:TDAUDO $>2.0$. CO;2.

Small, D., E. Atallah, and J. R. Gyakum, 2014: An objectively determined blocking index and its Northern Hemisphere climatology. J. Climate, 27, 2948-2970, https://doi.org/10.1175/ JCLI-D-13-00374.1.

Stoelinga, M. T., 1996: A potential vorticity-based study of the role of diabatic heating and friction in a numerically simulated baroclinic cyclone. Mon. Wea. Rev., 124, 849-874, https://doi.org/10.1175/ 1520-0493(1996)124<0849:APVBSO > 2.0.CO;2.

Stohl, A., C. Forster, and H. Sodemann, 2008: Remote sources of water vapor forming precipitation on the Norwegian west coast at $60^{\circ} \mathrm{N}$-A tale of hurricanes and an atmospheric river. J. Geophys. Res., 113, D05102, https://doi.org/10.1029/2007JD009006.

Strickler, W. R., E. A. Ritchie, and K. M. Wood, 2016: Investigating high impact weather events over the western United States downstream of extratropically transitioning tropical cyclones using the GEFS/R. 32nd Conf. on Hurricanes and Tropical Meteorology, San Juan, Puerto Rico, Amer. Meteor. Soc., https:// ams.confex.com/ams/32Hurr/webprogram/Paper293611.html.

Swinbank, R., and Coauthors, 2016: The TIGGE Project and its achievements. Bull. Amer. Meteor. Soc., 97, 49-67, https:// doi.org/10.1175/BAMS-D-13-00191.1.

Teubler, F., and M. Riemer, 2016: Dynamics of Rossby wave packets in a quantitative potential vorticity-Potential temperature framework. J. Atmos. Sci., 73, 1063-1081, https://doi.org/ 10.1175/JAS-D-15-0162.1.

Thorncroft, C. D., B. J. Hoskins, and M. E. McIntyre, 1993: Two paradigms of baroclinic-wave life-cycle behaviour. Quart. J. Roy. Meteor. Soc., 119, 17-55, https://doi.org/10.1002/qj.49711950903.

Torn, R. D., 2010: Diagnosis of the downstream ridging associated with extratropical transition using short-term ensemble forecasts. J. Atmos. Sci., 67, 817-833, https://doi.org/10.1175/2009JAS3093.1.

_ 2017: A comparison of the downstream predictability associated with ET and baroclinic cyclones. Mon. Wea. Rev., 145, 4651-4672, https://doi.org/10.1175/MWR-D-17-0083.1.

_ , and G. J. Hakim, 2009: Initial condition sensitivity of western Pacific extratropical transitions determined using ensemblebased sensitivity analysis. Mon. Wea. Rev., 137, 3388-3406, https://doi.org/10.1175/2009MWR2879.1.

$\longrightarrow$, and — 2015: Comparison of wave packets associated with extratropical transition and winter cyclones. Mon. Wea. Rev., 143, 1782-1803, https://doi.org/10.1175/MWR-D-14-00006.1.

_ J. S. Whitaker, P. Pegion, T. M. Hamill, and G. J. Hakim, 2015: Diagnosis of the source of GFS medium-range track errors in Hurricane Sandy (2012). Mon. Wea. Rev., 143, 132152, https://doi.org/10.1175/MWR-D-14-00086.1.

Vitart, F., and Coauthors, 2017: The Subseasonal to Seasonal (S2S) Prediction project database. Bull. Amer. Meteor. Soc., 98, 163173, https://doi.org/10.1175/BAMS-D-16-0017.1.

Wandishin, M. S., J. W. Nielsen-Gammon, and D. Keyser, 2000: A potential vorticity diagnostic approach to upper-level frontogenesis within a developing baroclinic wave. J. Atmos. Sci., 57, 3918-3938, https://doi.org/10.1175/1520-0469(2001)058<3918: APVDAT $>2.0 . \mathrm{CO} ; 2$.

Wang, Y., Y. Wang, and H. Fudeyasu, 2009: The role of Typhoon Songda (2004) in producing distantly located heavy rainfall in Japan. Mon. Wea. Rev., 137, 3699-3716, https://doi.org/10.1175/ 2009MWR2933.1.

Weissmann, M., and Coauthors, 2011: The influence of assimilating dropsonde data on typhoon track and midlatitude forecasts. Mon. Wea. Rev., 139, 908-920, https://doi.org/10.1175/ 2010MWR3377.1.

Wilks, D. S., 2011: Statistical Methods in the Atmospheric Sciences. 3rd ed. International Geophysics Series, Vol. 100, Academic Press, 704 pp.

Wirth, V., M. Riemer, E. K. M. Chang, and O. Martius, 2018: Rossby wave packets on the midlatitude waveguide-A review. Mon. Wea. Rev., 146, 1965-2001, https://doi.org/10.1175/MWR-D-16-0483.1.

Wu, C.-C., S.-G. Chen, J.-H. Chen, K.-H. Chou, and P.-H. Lin, 2009: Interaction of Typhoon Shanshan (2006) with the midlatitude trough from both adjoint-derived sensitivity steering vector and potential vorticity perspectives. Mon. Wea. Rev., 137, 852-862, https://doi.org/10.1175/2008MWR2585.1.

Zadra, A., and Coauthors, 2018: Systematic errors in weather and climate models: Nature, origins, and ways forward. Bull. Amer. Meteor. Soc., 99, ES67-ES70, https://doi.org/10.1175/ BAMS-D-17-0287.1.

Zhu, Y., and R. E. Newell, 1998: A proposed algorithm for moisture fluxes from atmospheric rivers. Mon. Wea. Rev., 126, 725-735, https:// doi.org/10.1175/1520-0493(1998)126<0725:APAFMF>2.0.CO;2. 